\title{
Estratigrafía y Sedimentología del relleno detrítico del estuario del Río Urumea (Donostia-San Sebastián, España)
}

José Miguel Edeso-Fito, Ángel Soria-Jáuregui, Ane Lopetegi-Galarraga, José Antonio Mujika-Alustiza, Mónica Ruiz-Alonso

José Miguel Edeso-Fito Ane Lopetegi-Galarraga

Departamento de Ingeniería Minera y

Metalúrgica y Ciencias de los Materiales, Universidad del País Vasco. C/ Rafael Moreno

'Pitxitxi', n’ 2, 48013 Bilbao (España)

Departamento de Geografía, Prehistoria y Arqueología, Universidad del País Vasco. C/

Tomás y Valiente s/n 01006 Vitoria - Gasteiz (España)

\section{Ángel Soria-Jáuregui}

José Antonio Mujika-Alustiza

angel.soria@ehu.eus

Departamento de Geografía, Prehistoria y Arqueología, Universidad del País Vasco. C/

Tomás y Valiente s/n 01006 Vitoria - Gasteiz (España)

\section{Mónica Ruiz-Alonso}

G. I. Arqueobiología. Instituto de Historia. Centro de Ciencias Humanas y Sociales, Consejo Superior de Investigaciones Científicas (CSIC). C/ Albasanz, n 26-28, 28047 Madrid (España).

BOL. SOC. GEOL. MEX. 2017 VOL. 69 NO. 1

P. $175-197$

\section{RESUMEN}

El análisis y caracterización del relleno sedimentario del estuario del Urumea permite diferenciar 2 sucesiones deposicionales distintas, separadas por un largo período cronológico sin registro sedimentario. La primera de estas sucesiones, de edad Pleistocena ( $>43500 \mathrm{BP}$ ) está formada por una facies palustre sobre la que se desarrollan facies fluvio-estuarinas, señalando un nivel marino similar o algo más bajo que el actual, lo que permite descartar las fases más frías del Pleistoceno. Sobre esta sucesión se desarrolla otra de edad Holocena que abarca el período comprendido entre el 7040 $\pm 30 \mathrm{BP}(7565-7390 \mathrm{cal}$. BP $)$ y la época actual. Se reconocen 3 pulsos transgresivos separados o seguidos por fases de estabilización o de regresión. La primera fase transgresiva se inició con anterioridad al $7040 \pm 30$ BP $(7565-7390$ cal. BP) y ya había concluido en el $5200 \pm 30$ BP (5995-5910 cal. BP). Alrededor de esta última fecha tiene lugar una breve pulsación regresiva que sitúa el nivel del mar varios metros por debajo de su posición actual. A partir del $5200 \pm 30$ BP $(5995-5910 \mathrm{cal}$. BP $)$ se constata un rápido ascenso del nivel del mar, seguido de una fase de estabilización primero y de discreta regresión después, que es aprovechada por grupos humanos para construir 2 rampas de uso desconocido. La cronología de esta fase regresiva se sitúa en torno al $4710 \pm 30$ BP (4945-4650 cal. BP). Una nueva pulsación transgresiva tiene lugar a partir del $3000 \mathrm{BP}$ prolongándose mediante una suave elevación hasta el $1240 \pm 30 \mathrm{BP}(1190-1065 \mathrm{cal}$. BP $)$. La estabilización (y quizás una nueva oscilación en época histórica) del nivel del mar a partir de esta fecha favorece la colmatación del estuario, lo que unido a la formación de un tómbolo en la margen izquierda determina el desarrollo de un estuario semi-cerrado que pervive hasta la actualidad.

Palabras clave: Holoceno, Pleistoceno, transgresión, regresión, nivel del mar, rampas antrópicas.

\begin{abstract}
Two different depositional phases can be identified in the Urumea estuarine infill. They were chronologically separated by a long period without sedimentological evidence. The first one, Pleistocene in age (> $43500 \mathrm{BP})$, is composed of a marsh facies overlaid by fluvio-estuarine facies. This could indicate that the sea level at the time was similar or slightly lower than the present parameter. The later information rules out the coldest stages of the Pleistocene as their origin. On top of the uppermost Pleistocene layer, a Holocene sequence developed which extends from $7040 \pm$ 30 BP $(7565-7390$ cal. BP) to modern times. In this part of the infill, 3 transgressive pulses can be identified, separated or followed by phases of sea level stabilization or even regression. The first pulse began before $7040 \pm 30 \mathrm{BP}(7565-$ $7390 \mathrm{cal} . \mathrm{BP})$ and extended to $5200 \pm 30$ BP (5995-5910 cal. BP). The first regressive pulse took place around the last date, placing the shoreline a few meters below its present position. After $5200 \pm 30$ BP (5995-5910 cal. BP), a fast sea level rise can be recorded, followed by a stabilisation phase first. Also, a minor regression happened afterwards, which was used by local communities to build two ramps of unknown utility. This regressive pulse was dated $4710 \pm$ 30 BP (4945-4650 cal. BP). A new transgressive pulse took place after 3000 BP extending through a gentle sea level rise to $1240 \pm 30 \mathrm{BP}$ (1190-1065 cal. BP). From this date, sea level stabilisation (and maybe a new transgression in historical times) favoured the total infilling of the estuary, which, together with the development of a tombolo on the left bank, induced the formation of a semi-enclosed estuary which can still be observed nowadays.
\end{abstract}

Keyzords: Holocene, Pleistocene, transgression, regression, sea level, anthropic ramps. 


\section{Introducción}

Los estuarios se definen como paleovalles fluviales inundados, generados por la interacción del oleaje, las mareas y la dinámica fluvial (Vilas, 1989). De esta definición se deriva que los estuarios se extienden desde el límite superior de influencia mareal hasta el límite inferior de influencia costera (Davies, 1964; Hayes, 1975; Reineck y Singh, 1980). Resultados obtenidos en varios estuarios indican que la inundación de estos paleovalles se produjo como consecuencia del rápido ascenso del nivel del mar tras el mínimo alcanzado durante el Último Máximo Glaciar (Milliman y Emery, 1968; Liu y Milliman, 2004; Milne et al., 2005; Bard et al., 2010). Este cambio de nivel de base generó profundas alteraciones en la dinámica deposicional, permitiendo la sedimentación continuada de una sucesión detrítica generada, inicialmente, por una dinámica fluvial que posteriormente evoluciona hacia estadios estuarinos y/o francamente marinos (Reineck y Singh, 1980).

La costa noreste del Atlántico Norte y específicamente la línea de costa situada en el Golfo de Bizkaia (o Golfo de Gascuña) está caracterizada por la presencia de diversos estuarios (Bailey, 1995; Tenore et al., 2006; Hume et al., 2007; Galván, 2014), cada uno de los cuales presenta características y dinámicas diferentes. Los estudios realizados hasta la fecha muestran que la sedimentación en estos ambientes estuarinos comenzó en torno al 85009000a BP (Edeso-Fito, 1991, 1992, 1994; Blanco-Chao et al., 2002; Edeso-Fito y Mujika-Alustiza, 2005; Flor y Lharti, 2008; Leorri y Cearreta, 2009; Alonso y Pagés, 2010), ralentizándose e incluso estabilizándose entre el 7000 y el 3000 (sin descartar una o varias fases regresivas durante este lapso de tiempo) constatándose una nueva pulsación transgresiva a partir del $3000 \mathrm{BP}$ (Edeso-Fito, 1991, 1992; Edeso-Fito y Mujika-Alustiza, 2005; Leorri y Cearreta, 2009; Alonso y Pagés, 2010; Leorri et al., 2012).
Esta última pulsación determina un proceso de colmatación, favorecido por la antropización del medio (roturación y deforestación a partir del Neolítico), lo que dispara la producción de sedimentos en muchos ámbitos territoriales (Milliman y Emery, 1968; Edeso-Fito, 1992; Leorri y Cearreta, 2009; Alonso y Pagés, 2010). Un buen ejemplo de todo ello, con evidentes indicios de intervención humana, es el estuario objeto de estudio, ya que en él se recoge una sucesión detrítica Holocena (sobre otra Pleistocena incompleta) en cuyo interior se detectan construcciones de origen antrópico cuya finalidad parece vincularse con la explotación de recursos marinos.

El principal objetivo de este artículo es la caracterización del relleno detrítico existente en el estuario del Río Urumea (País Vasco, España), de cara a proponer un modelo evolutivo de la formación del estuario y contribuir, con los datos aportados, a una futura elaboración de una curva en la que se refleje la evolución del nivel del mar durante el Holoceno, ya que la información disponible hasta el momento no es del todo coherente, existiendo diversas discrepancias a la hora de fijar tanto la cronología como la altura alcanzada por el nivel del mar en estos ámbitos. Para ello se ha realizado la caracterización sedimentológica, estratigráfica, paisajística y cronológica de los sedimentos encontrados, estableciéndose a partir de estos datos las principales secuencias evolutivas.

\section{Descripción de área de trabajo}

El estuario del Río Urumea se localiza en el extremo septentrional de la Península Ibérica y, más concretamente, en el sector nororiental de la Comunidad Autónoma del País Vasco, en la ciudad de Donostia-San Sebastián (Figura 1A). Dicho estuario se encuentra en el dominio estructural de la Cuenca Vasco-Cantábrica (CVG), unidad invertida durante la Orogenia Alpina que sirve de 
enlace entre los Pirineos y la Cordillera Cantábrica (Barnolas y Pujalte, 2004). Dentro de la CVC, el estuario ocupa parte del extremo nororiental de la subunidad más fuertemente plegada, el Arco Plegado Vasco, un conjunto de morfoestructuras plegadas de vergencia norte (Feuillée y Rat, 1971; Figura 1B). En las inmediaciones de Donostia-San Sebastián estas unidades se traducen en un relieve de media montaña articulado en una serie de colinas de fuertes pendientes y cima redondeada, que se disponen flanqueando el amplio estuario del Urumea.

El estuario tiene una longitud de $7.7 \mathrm{~km}$ y es muy poco profundo, quedando prácticamente vaciado durante la bajamar, hasta tal punto que apenas dibuja un canal somero, funcionando como una ría de vaciado (Ibáñez et al., 2009). Está afectado por mareas semidiurnas, con 2 pleamares y 2 bajamares en algo más de 24 horas, oscilando la amplitud de la marea entre $1 \mathrm{~m}$ en las mareas muertas, hasta
$4.5 \mathrm{~m}$ en las mareas vivas, siendo la onda de marea de tipo standing (Ketchum, 1983).

La caracterización de los sedimentos del estuario se ha realizado en un solar localizado en el municipio de Donostia-San Sebastián, en la margen derecha del estuario del Urumea, a $1.2 \mathrm{~km}$ de su actual desembocadura (Figura 1C). Altimétricamente, el techo del relleno se sitúa entre los 2.37 y los $2.99 \mathrm{~m}$ por encima del nivel máximo alcanzado por la pleamar ${ }^{b}$. El sustrato rocoso está constituido por una alternancia de margas, calizas arenosas, calizas arcillosas, calizas, argilitas y areniscas (fyssch detrítico-carbonatado) estratificadas en bancos centi-decimétricos de edad Campaniense-Maastrichtiense (Cretácico Superior), con valores de buzamiento que oscilan entre los 20 y los $65^{\circ} \mathrm{N}$ (Garrote et al., 1990). Por encima de esta serie cretácica se ha depositado un relleno sedimentario cuya potencia oscila entre los $13 \mathrm{~m}$ y los $17.55 \mathrm{~m}$.

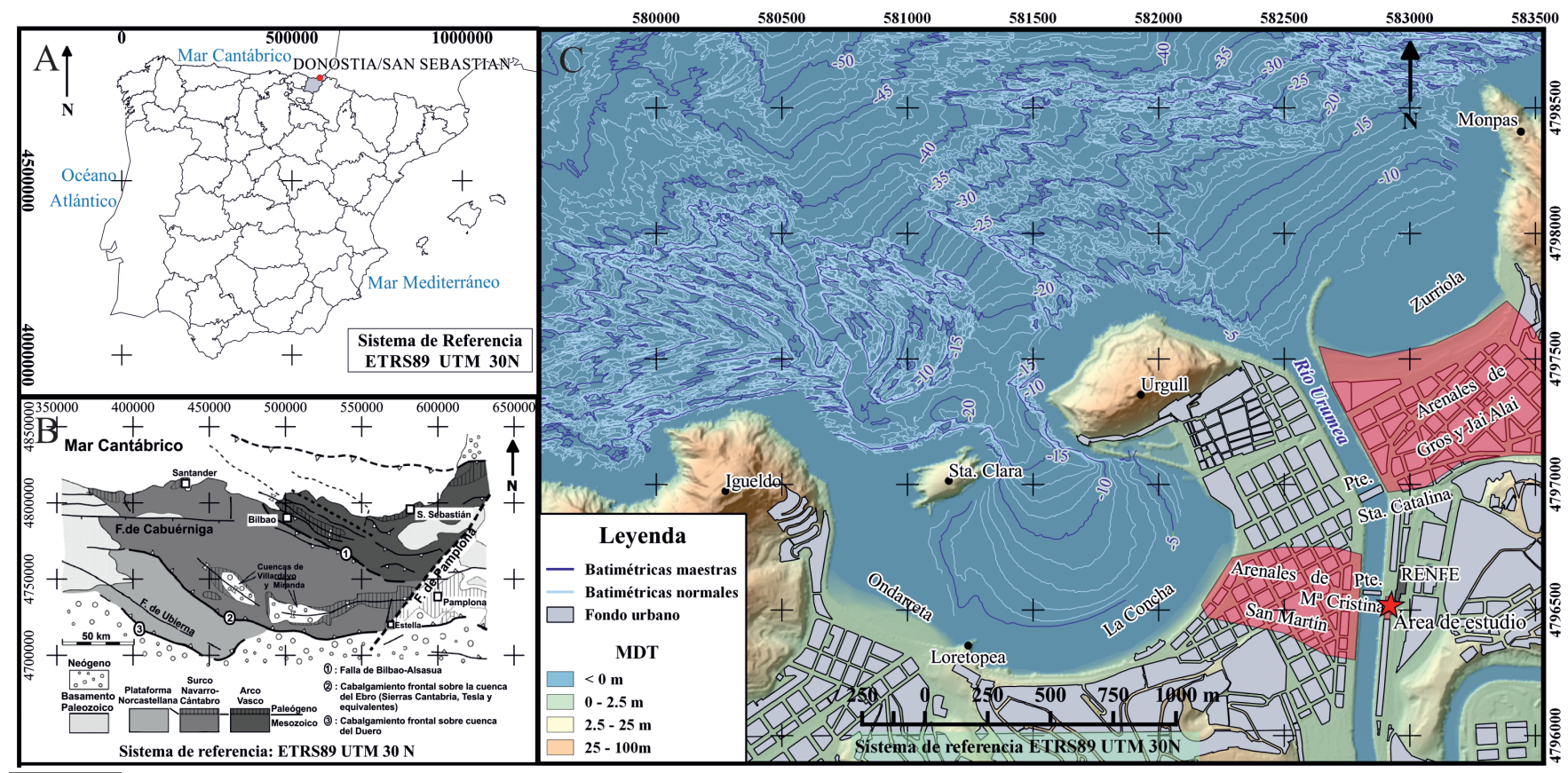

Figura 1 Mapa de localización del área de estudio. A) Península Ibérica; B) Cuenca Vasco-Cantábrica (modificado de Vera, 2004); C) Mapa de Donostia - San Sebastián. La estrella roja marca el lugar del área de estudio

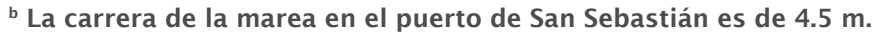




\section{Métodos}

A finales del 2014 se iniciaron las tareas de vaciado del solar en el que se ha construido la estación de autobuses de Donostia-San Sebastián — junto al puente María Cristina y la estación de RENFE(Figura 1C), permitiendo realizar un análisis exhaustivo del relleno sedimentario allí existente y tomar 140 muestras que posteriormente fueron analizadas en el laboratorio de Sedimentología de la Escuela de Ingenieros de Vitoria-Gasteiz (País Vasco, España). Esta información se complementó con la suministrada por diversos trabajos geotécnicos (sondeos mecánicos) efectuados como consecuencia de los proyectos de construcción de la mencionada estación y del futuro tren de alta velocidad, así como por otras procedentes tanto de áreas próximas (sondeos mecánicos y muestreos en el tómbolo de San Sebastián) como de las playas actuales.

Cada una de las muestras ha sido sometida a un análisis granulométrico mediante tamizado en seco para las fracciones mayores de $50 \mu \mathrm{m}$ (Folk y Ward, 1957; Visher, 1969; Folk, 1974; Reineck y Singh, 1980), complementándose esta información mediante el análisis morfoscópico de los granos de arena, utilizando para ello un binocular de 30 aumentos (Powers, 1953; Shepard, 1963). El color de los sedimentos se describió en las muestras secas del laboratorio utilizando los códigos de color Munsell. El análisis de los limos y arcillas se ha realizado mediante el método densimétrico de Meriaux (1953). Los resultados de estos análisis han sido tratados mediante el programa Gradistat (Blott y Pye, 2001), plasmándose la información en una columna estratigráfica, junto con la representación de sus parámetros granulométricos (Tablas 2 y 3 Figura 2). Estos valores aportan información sobre las condiciones deposicionales del sedimento, ya que cuando ésta es libre los histogramas tienden a ser unimodales, con curvas hiperbólicas o sigmoidales enderezadas y selección y clasificación buena, mientras que cuando la sedimentación es forzada las curvas tienden a ser parabólicas o sigmoidales muy tendidas, los histogramas polimodales y la selección y clasificación mala (Cailleux y Tricart, 1961; Vatan, 1967; Reineck y Singh, 1980; Sanjaume, 1985).

La identificación de los fragmentos de madera se ha efectuado en los Laboratorios de Arqueobotánica del Instituto de Historia en el Centro Ciencias Humanas y Sociales del Consejo Superior de Investigaciones Científicas de España (CSIC). Éstos se han examinado en un microscopio de luz incidente Leica DM 4000M (50x/100x/200x/500x) en sus secciones transversal, longitudinal radial y longitudinal tangencial. La identificación se ha efectuado mediante la comparación de las características anatómicas del material arqueológico, con la colección de referencia de maderas modernas del mencionado laboratorio, así como consultando los atlas de anatomía de la madera de Schweingruber (1990), Hather (2000) y Vernet et al. (2001). Por último, se han datado los niveles de carbono-14 mediante espectrometría de masas con aceleradores (AMS) de 9 muestras en los laboratorios Beta Analytic Inc (Miami, EEUU).

\section{Resultados}

\subsection{DESGRIPGIÓN DEL RELLENO DETRÍTICO DEL SOLAR INVESTIGADO}

Incluyendo los materiales recientes de origen antrópico, el relleno sedimentario tiene una potencia que oscila entre los 13 y los $17.55 \mathrm{~m}$, pudiendo diferenciarse, de muro a techo, 14 unidades sedimentarias cuyas características granulométricas se recogen en la Tabla 1 así como en la Figura 2:

\subsubsection{UNIDAD LIMO-ARENOSA BASAL (-14.56 A -13.23 $\left.m^{c}\right)$}

Únicamente está presente en el sector noroccidental de la parcela y, más concretamente, en el punto 
en el que el relleno alcanza su mayor desarrollo. Es un sedimento limo-arenoso de color gris oscuro sin elementos gruesos. Tiene un espesor máximo de $133 \mathrm{~cm}$, no habiéndose podido determinar su morfología al no poder observarse el contacto con el sustrato rocoso subyacente (el espesor se ha obtenido a partir de un sondeo geotécnico efectuado en las proximidades). El sedimento presenta laminación paralela bioturbada, conteniendo abundantes macro-restos vegetales (hojas, tallos y ramas), así como un elevado porcentaje de materia orgánica $(8.2 \%)$. La fracción arenosa fluctúa entre el 28 y el $31 \%$, predominando claramente las arenas finas. Las dataciones mediante carbono-14 indican que su edad supera el rango máximo de medición, es decir, los 43500 años (Beta-407178) (Tabla 1; Figura 2).

\subsubsection{UNIDAD ARENO-LIMOSA CON GRAVAS Y CANTOS $(-13.23 \mathrm{~A}-12.88 \mathrm{~m})$}

Tiene una potencia máxima observable de $35 \mathrm{~cm}$, aunque no hemos podido ver el nivel completo ya que en el momento del muestreo había sido decapitado. El contacto con el nivel subyacente es claramente erosivo, dibujándose una serie de surcos de amplitud métrica. Está constituido por gravas y cantos rodados empastados en una matriz areno-limosa de color gris oscuro, dentro de la cual se observan abundantes macro-restos vegetales, así como algunas conchas entre las que se reconocen ostreidos, turritelados y Natica sp. La fracción gruesa representa el $73.43 \%$ del total analizado y está constituida por gravas $(<2 \mathrm{~cm})$ y cantos pequeños $(2-6 \mathrm{~cm})$ de arenisca, esquisto más o menos micáceo, cuarzo y caliza, presentando diversos grados de alteración y redondez (oscilan entre muy rodados y subredondeados). El centilo, tamaño del clasto más grande que existe en el depósito, apenas alcanza los $3.4 \mathrm{~cm}$. La fracción arenosa supone el $57.5 \%$ del total de finos analizados, predominando las arenas finas $(59.5 \%$ ), aunque las gruesas también están bien representadas $(32.4 \%)$. Aunque las condiciones de observación no han sido las más adecuadas, se detecta una estructura groseramente lenticular que parece relacionarse con un paleocanal fluvial o fluvio-mareal de dimensiones discretas. Lateral y longitudinalmente no hemos podido determinar la continuidad del nivel, desarrollándose sobre el sustrato rocoso materiales que nada tienen que ver con los reseñados anteriormente (Tabla 2; Figura 2).

\subsubsection{UNIDAD LIMO-ARENOSA/ARENO-LIMOSA (-12.88 Y LOS $-12.28 \mathrm{~m})$}

Entre los -12.88 y los $-12.28 \mathrm{~m}$ se desarrolla un nivel limo-arenoso/areno-limoso de color gris-negro en húmedo, con abundantes fragmentos angulosos de roca, cuyo origen se relaciona con la meteorización del sustrato rocoso subyacente o próximo. Tiene una potencia media de $40 / 60 \mathrm{~cm}$ y una morfología irregular y discontinua. La fracción gruesa representa el $83 \%$ del total analizado y está constituida por areniscas y calizas muy alteradas, procedentes del sustrato rocoso y cuarzos lechosos poco rodados, junto con abundantes fragmentos de conchas y macro-restos vegetales gruesos. En lo que se refiere a la fracción fina predominan los limos y las arcillas, aunque las arenas también están bien representadas, incrementándose paulatinamente de muro a techo, pasando del 31.6 al $44.01 \%$, predominando en todos los casos las arenas finas. En este nivel se han recogido muestras de una rama o tronco grande. En su observación al microscopio ha sido imposible observar su estructura anatómica debido a la vitrificación completa del elemento. Su edad supera los 43500 años (Beta-405042) (Tablas 1 y 2; Figura 2).

\subsubsection{UNIDAD ARENOSA (-12.23 A -11.18 m)}

Tiene una potencia media de $105 \mathrm{~cm}$ presentando un contacto sinuoso con el nivel detrítico subyacente. La fracción gruesa es abundante y presenta una tendencia granodecreciente, disminuyendo del $63.8 \%$ a muro al $22.7 \%$ a techo. Está constituida por gravas y cantos pequeños (centilo: 6.6 $\mathrm{cm}$ de arenisca), angulosos o ligeramente rodados de arenisca, caliza y cuarzo, junto con conchas (enteras y rotas) de Ostrea edulis, Cerastoderma edule, Mytilus galloprovincialis, turritelados y pectínidos. Se han recogido también espículas de erizo y fragmentos de pinzas de cangrejo. La fracción arenosa se incrementa de muro a techo pasando del 75 al 
$82 \%$. Predominan, en todos los casos, las arenas finas. No se observan remociones postdeposicionales, ni fluctuaciones energéticas significativas. La fracción gruesa tiene un origen local o a lo sumo ha sido removilizada desde entornos próximos, de ahí que presente un reducido grado de redondez. Únicamente los cuarzos lechosos no están presentes en la zona, aunque es probable que se trate de materiales residuales de origen fluvial (Tabla 2; Figura 2).

\subsubsection{UNIDAD ARENOSA MUY RICA EN BIOCLASTOS (-11.18 A -10.93 m)}

Constituye un nivel bastante homogéneo de color amarillento, presentando un contacto planar con la unidad subyacente. La fracción gruesa representa el $21.7 \%$ del total analizado y está constituida por algunas gravas de arenisca y cuarzo, sumamente rodadas y, sobre todo por conchas, enteras y rotas-, de Ostrea edulis, Cerastoderma edule, Mytilus galloprovincialis, turritelados y diversos tipos de gasterópodos. En su mayor parte es una fauna típica de sustratos duros que no presenta huellas de rodamiento. La fracción fina es claramente arenosa $(>91 \%)$, predominando las arenas finas (Tabla 2; Figura 2).

\subsubsection{UNIDAD DE ARENAS ROJAS/NARANJAS (-10.93 A $-10.83 \mathrm{~cm}$ )}

Está constituida, casi exclusivamente, por restos bioclásticos teñidos por óxidos de hierro (color naranja en húmedo). La fracción gruesa supone el $10.34 \%$ del total y está formada por conchas ente- ras y fragmentos bioclásticos entre los que podemos reconocer Corbula gibba, Ostrea edulis, Cerastoderma edule, Dentalium sp., Pectínidos, Turritelados..., así como algunas gravas rodadas de arenisca y caliza. La fracción arenosa se eleva hasta el $97.8 \%$ del total de finos analizados, predominando claramente las arenas gruesas (> 50 \%). La datación de esta unidad mediante carbono-14 arroja una edad de $7040 \pm 30$ BP (7565-7390 cal. BP) (Beta429908) (Tablas 1 y 2; Figura 2).

\subsubsection{UNIDAD ARENOSA (-10.83 A -6.83 m)}

Tiene un espesor de $4 \mathrm{~m}$, observándose diversas estructuras sedimentarias a lo largo del perfil, así como variaciones granulométricas significativas, con una cierta tendencia granodecreciente. El contacto con el nivel subyacente es planar, mientras que con el suprayacente es de tipo sinuoso (surcos y microcanales).

Los primeros $2 \mathrm{~m}$ presentan estructuras plano-paralelas, interrumpidas lateralmente por estructuras canaliformes constituidas por materiales más gruesos. En la base se han recogido abundantes restos vegetales que se disponen formando un lecho de $3 \mathrm{~cm}$ de potencia. Los diversos análisis efectuados ponen de manifiesto que se trata de una acumulación de hojas compactadas, pero no es posible identificarlas a nivel taxonómico debido a lo frágil del material. Las dataciones efectuadas mediante carbono-14 arrojan una edad de 5910 \pm 30 BP (6790-6665 cal. BP) (Beta-407189). La

Tabla 1. Muestras utilizadas para su datación por radiocarbono.

\begin{tabular}{|c|c|c|c|c|}
\hline Unidad & Referencia & Material datado & Datación C-14 no calibrada & Datación C-14 calibrada \\
\hline a & Beta 407178 & Restos vegetales diversos & $>43500$ & \\
\hline c & Beta 405042 & Madera & $>43500$ & \\
\hline f & Beta 429908 & Conchas & $7040 \pm 30 \mathrm{BP}$ & $7565-7390 \mathrm{cal}$. BP \\
\hline g & Beta 407189 & Hojas & $5910 \pm 30 \mathrm{BP}$ & $6790-6665 \mathrm{cal}$. BP \\
\hline h & Beta 405047 & Hojas & $5200 \pm 30 \mathrm{BP}$ & $5995-5910 \mathrm{cal}$. BP \\
\hline j & Beta 407176 & Conchas & $4710 \pm 30 \mathrm{BP}$ & $4945-4650 \mathrm{cal}$. BP \\
\hline k & Beta 407190 & Madera & $2810 \pm 30 \mathrm{BP}$ & $2970-2850 \mathrm{cal}$. BP \\
\hline 1 & Beta 405048 & Madera & $2770 \pm 30 \mathrm{BP}$ & $2950-2785 \mathrm{cal}$. BP \\
\hline l & Beta 405041 & Madera & $1220 \pm 30 \mathrm{BP}$ & $1190-1065 \mathrm{cal}$. BP \\
\hline
\end{tabular}




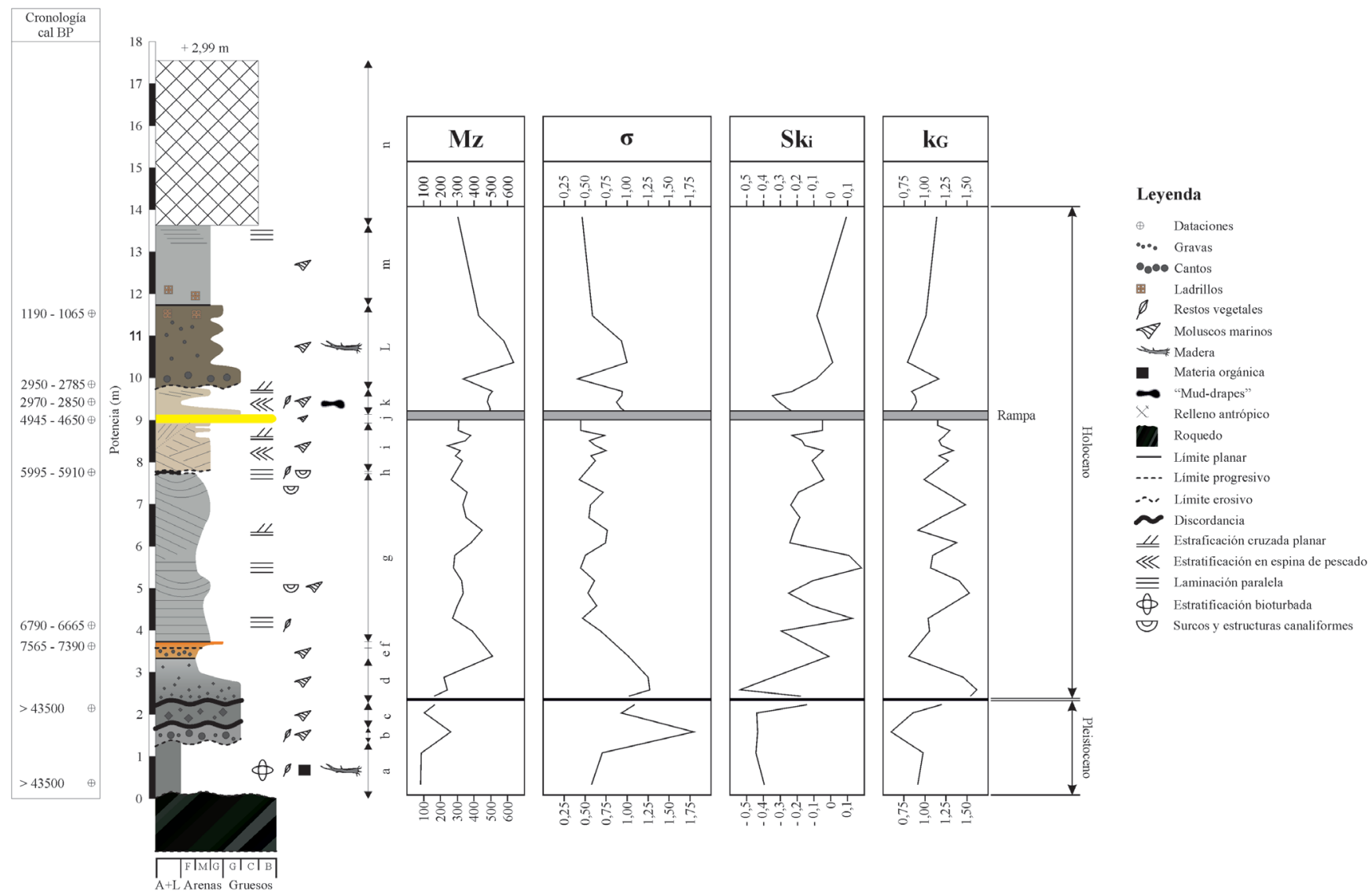

Columna estratigráfica junto con sus parámetros granulométricos. Mz = Media; $\sigma$ = clasificación; Ski = Skewness; $K G$ = Kurtosis.

fracción gruesa es escasa ya que oscila entre el 2 y el 8\% y está constituida por conchas (Mytilus galloprovincialis, Ostrea edulis y pectínidos), concreciones arenosas y algunas gravas de cuarzo. La fracción fina es fundamentalmente arenosa $(>98 \%)$ predominando las arenas medias (> $53 \%$ ) excepto en el techo del subnivel dónde las finas son dominantes $(70.6 \%)$.

El tramo superior muestra una alternancia de lechos de distinta granulometría e incluso algunos parcialmente cementados de color blanquecino, constituidos en gran medida por conchuela triturada. Todo el conjunto presenta estratificación cruzada y contactos erosivos con el nivel suprayacente. La fracción gruesa fluctúa considerablemente a lo largo del perfil, con tramos en los que apenas supone el 2-3\% junto a otros en los que se rebasa el $23 \%$. Una parte significativa de esta fracción está constituida por concreciones arenosas y por restos bioclásticos (espículas de erizos, Mytilus edulis, Cerastoderma edule, Monodonta lineata, Corbula gibba, Mya arenaria, turritelados, pectínidos...), siendo escasas las gravas. La fracción fina es claramente arenosa (> $99 \%$ ) predominando en todos los casos las arenas medias $(50-70 \%)$, aunque a techo las arenas finas también están bien representadas (Tablas 1 y 2; Figura 2).

\subsubsection{UNIDAD ORGÁNICA (-6.83 A -6.78 m)}

El nivel arenoso anterior termina bruscamente mediante una superficie erosiva en la que se han modelado diversos surcos. El más importante tiene $112 \mathrm{~cm}$ de anchura por $37 \mathrm{~cm}$ de profundidad. En su interior se acumulan macro-restos vegetales ( $5 \mathrm{~cm}$ de potencia máxima) que han sido datados mediante carbono- 14 arrojando una edad de 
$5200 \pm 30$ BP (5995-5910 cal. BP) (Beta-405047). No hay sedimento entre los lechos de materia orgánica. También en este caso se trata de hojarasca (muy frágil) y aunque tiene un color ceniciento no se observan elementos carbonizados (Tablas 1 y 2; Figura 2 y Figura 3B).

\subsubsection{UNIDAD ARENOSA (-6.78 A -5.63 m)}

Colmatando los surcos anteriores, se dispone un nivel arenoso con estratificación en espina de pescado. La fracción gruesa apenas representa el 1.6 $\%$ y está constituida mayoritariamente por fragmentos de conchas (Corbula gibba, Mytilus edulis), espículas de erizo, junto con algunas gravas rodadas. A su vez, sobre este tramo se desarrolla un paquete de arenas con estratificación cruzada planar. La fracción arenosa es claramente dominante ya que supera el $99 \%$ del total de finos analizado. Predominan las arenas medias (54/62\%) aunque las finas también están bien representadas. En la parte superior la fracción gruesa se incrementa considerablemente, pudiendo llegar a suponer el $32 \%$ del total analizado. Está constituida por concreciones arenosas, gravas rodadas y cantos (centilo: $6.7 \mathrm{~cm}$ de caliza) y, sobre todo, por conchas, —enteras y rotas-, de Mytilus galloprovincialis, Mytilus edulis, Donax vittatus, Ostrea edulis, Callista chione, Corbula gibba, Cerastoderma edule, Tellina fabula, Patella vulgata y turritelados. La fracción arenosa es dominante (>98\%), destacando las arenas medias, aunque se constatan algunos niveles en los que son dominantes las arenas finas $(56 / 66 \%)$ (Tabla 2).

\subsubsection{RAMPAS DE ORIGEN ANTRÓPICO (-5.63 A -5.43 m)}

Se han identificado 2 rampas paralelas entre sí (una más corta que la otra) separadas por unos 40 m de distancia. Ambas están constituidas por cantos y bloques rodados, de morfología aplanada y de litología local (areniscas y distintos tipos de calizas), presentando muchos de ellos huellas evidentes de haber estado sumergidos en un ambiente salino, ya que presentan incrustaciones de conchas, pudiendo reconocerse Ostrea edulis, Mytilus galloprovincialis, (ambas valvas) Balanus balanus, Fissurella spp., Littorina littorea y Anomia ephippium. Los

Tabla 2. Características granulométricas y sedimentológicas de las diferentes unidades analizadas.

\begin{tabular}{|c|c|c|c|c|c|c|c|c|c|}
\hline \multirow[b]{2}{*}{ Unidad } & \multirow[b]{2}{*}{ Descripción } & \multirow[b]{2}{*}{ Color } & \multirow[b]{2}{*}{ Estruc. Sed. } & \multicolumn{6}{|c|}{ Datos granulométricos de las arenas } \\
\hline & & & & $\begin{array}{c}\text { Media } \\
\mu \mathrm{m}\end{array}$ & $\begin{array}{c}\text { Clasificación } \\
\varphi\end{array}$ & $\begin{array}{c}\text { Asimetría } \\
\varphi\end{array}$ & $\begin{array}{c}\text { Kurtosis } \\
\varphi\end{array}$ & Histograma & Curva acumulativa \\
\hline $\begin{array}{l}\mathrm{a}-14.56 /- \\
13.23\end{array}$ & $\begin{array}{l}\text { Potencia métrica }(133 \mathrm{~cm}) \text { con base no } \\
\text { visible }\end{array}$ & $\begin{array}{l}2.5 \text { Y } 5 / 110 \text { YR } \\
4 / 110 \text { YR } 5 / 1\end{array}$ & $\begin{array}{l}\text { Laminación paralela } \\
\text { bioturbada }\end{array}$ & $81 / 86$ & $\begin{array}{l}\text { Bien y moderadamente } \\
\text { bien }\end{array}$ & Negativa & Mesocúrtica & Unimodales & Hiperbólica enderezadas \\
\hline $\begin{array}{l}\mathrm{b}-13.23 /- \\
12.88\end{array}$ & $\begin{array}{l}\text { Potencia decimétrica }(35 \mathrm{~cm}) \text {, contacto } \\
\text { basal erosivo }\end{array}$ & $\begin{array}{c}2.5 \text { Y } 5 / 1 \\
\text { Y } 6 / 1\end{array}$ & Masiva & 262.1 & Mal clasificado & Negativa & Muy platicúrtica & Polimodales & $\begin{array}{c}\text { Transicionales Parabólicas } \\
\text { y sigmoidales }\end{array}$ \\
\hline $\begin{array}{l}c-12.88 /- \\
12.28\end{array}$ & $\begin{array}{l}\text { Contacto erosivo sobre roquedo. } \\
\text { Superficie irregular y discontinua. } \\
\text { Potencia decimétrica }(60 \mathrm{~cm})\end{array}$ & $\begin{array}{c}2.5 \text { Y } 5 / 110 \text { YR } \\
4 / 110 \text { YR } 5 / 1\end{array}$ & Masiva & $105 / 166$ & $\begin{array}{l}\text { Moderadamente bien/ } \\
\text { mal clasificado }\end{array}$ & Negativa & $\begin{array}{c}\text { Platicúrtica/meso } \\
\text { cúrtica }\end{array}$ & $\begin{array}{l}\text { Unimodales/ } \\
\text { Bimodales }\end{array}$ & $\begin{array}{c}\text { Transicionales hiperbólicas } \\
\text { y sigmoidales }\end{array}$ \\
\hline $\begin{array}{l}d-12.28 /- \\
11.18\end{array}$ & $\begin{array}{l}\text { Potencia métrica }(105 \mathrm{~cm}) \text { y contacto } \\
\text { basal erosivo }\end{array}$ & $\begin{array}{c}10 \mathrm{YR} 4 / 110 \mathrm{YR} \\
7 / 1\end{array}$ & Masiva & $153 / 172$ & Mal clasificado & Negativa & Muy platicúrtica & $\begin{array}{l}\text { Unimodales/ } \\
\text { Bimodales }\end{array}$ & $\begin{array}{c}\text { Transicionales hiperbólicas } \\
\text { y sigmoidales }\end{array}$ \\
\hline $\begin{array}{l}\text { e }-11.18 /- \\
10.93\end{array}$ & $\begin{array}{l}\text { Unidad decimétrica }(25 \mathrm{~cm}) \text { con un } \\
\text { contacto basal planar neto }\end{array}$ & $\begin{array}{c}10 \text { YR } 7 / 610 \text { YR } \\
6 / 6\end{array}$ & Masiva & 220.3 & Mal clasificado & Negativa & Leptocúrtica & Bimodales & Hiperbólicas deformadas \\
\hline $\begin{array}{l}f-10.93 /- \\
10.83\end{array}$ & $\begin{array}{l}\text { Cuerpo decimétrico }(10 \mathrm{~cm}) \text { tabular con } \\
\text { contacto basal gradual }\end{array}$ & $\begin{array}{c}10 \text { YR } 7 / 610 \text { YR } \\
6 / 6\end{array}$ & Masiva & 510 & Mal clasificado & Simétrica & Platicúrtica & Bimodales & Parabólicas \\
\hline $\begin{array}{l}\text { g }-10.83 /- \\
6.83\end{array}$ & $\begin{array}{l}\text { Potencia métrica }(4 \mathrm{~m}) \text { con contacto } \\
\text { basal planar neto }\end{array}$ & 10 YR $7 / 1$ & $\begin{array}{l}\text { Laminación paralela, } \\
\text { cruzada planar }\end{array}$ & $415 / 254$ & $\begin{array}{l}\text { Bien/moderadamente } \\
\text { bien clasificado }\end{array}$ & $\begin{array}{l}\text { Negativa } \\
\text { Positiva }\end{array}$ & $\begin{array}{l}\text { Leptocúrtica } \\
\text { Mesocúrtica }\end{array}$ & Unimodales & Sigmoidales \\
\hline $\begin{array}{l}\mathrm{h}-6.83 /- \\
6.78\end{array}$ & $\begin{array}{l}\text { Unidad con base erosiva de potencia } \\
\text { centimétrica }(5 \mathrm{~cm})\end{array}$ & 10 YR $2 / 1$ & Laminación paralela & \multicolumn{6}{|c|}{ Acumulación de restos orgánicos } \\
\hline $\begin{array}{l}i-6.78 /- \\
5.63\end{array}$ & $\begin{array}{l}\text { Contacto basal erosivo. Potencia métrica } \\
(115 \mathrm{~cm})\end{array}$ & 2.5 Y $6 / 3$ & $\begin{array}{l}\text { Espina de pescado, } \\
\text { cruzada planar }\end{array}$ & $\begin{array}{l}290 / 330 \\
306 / 355\end{array}$ & $\begin{array}{l}\text { Moderadamente bien } \\
\text { clasificado }\end{array}$ & $\begin{array}{l}\text { Negativa } \\
\text { Positiva } \\
\text { Simétrica }\end{array}$ & Leptocúrtica & Unimodales & Sigmoidales \\
\hline $\begin{array}{l}j-5.63 /- \\
5.43\end{array}$ & - & - & - & \multicolumn{6}{|c|}{ Rampas de origen antrópico } \\
\hline $\begin{array}{l}\mathrm{k}-5.43 /- \\
4.83\end{array}$ & $\begin{array}{l}\text { Cuerpos lenticulares apoyados la rampa. } \\
60 \mathrm{~cm} \text { de potencia }\end{array}$ & 2.5 Y $6 / 3$ & $\begin{array}{l}\text { Espina de pescado, } \\
\text { cruzada planar }\end{array}$ & $480 / 509$ & $\begin{array}{l}\text { Mal/Moderadamente } \\
\text { clasificado }\end{array}$ & Negativa & Platicúrtica & $\begin{array}{c}\text { Polimodales/ } \\
\text { Bimodales }\end{array}$ & $\begin{array}{l}\text { Parabólicas Sigmoidales } \\
\text { tendidas }\end{array}$ \\
\hline $\begin{array}{l}1-4.83 /- \\
2.83\end{array}$ & $\begin{array}{l}\text { Potencia de } 200 \mathrm{~cm} \text { con un contacto } \\
\text { basal erosivo. }\end{array}$ & 2.5 Y $5 / 2$ & Masivo & $\begin{array}{l}492 / 582 \\
332 / 495\end{array}$ & $\begin{array}{l}\text { Mal/Moderadamente } \\
\text { clasificado }\end{array}$ & $\begin{array}{l}\text { Negativa } \\
\text { Simétrica }\end{array}$ & $\begin{array}{l}\text { Platicúrtica } \\
\text { Leptocúrtica }\end{array}$ & $\begin{array}{l}\text { Polimodales } \\
\text { Bimodales } \\
\text { Unimodales }\end{array}$ & $\begin{array}{l}\text { Parabólicas Sigmoidales } \\
\text { más o menos tendidas }\end{array}$ \\
\hline $\begin{array}{l}\mathrm{m}-2.83 /- \\
0.93\end{array}$ & Base planar y $190 \mathrm{~cm}$ de potencia. & 10 YR $7 / 1$ & $\begin{array}{l}\text { Laminación paralela, } \\
\text { masivo }\end{array}$ & $304 / 332$ & $\begin{array}{l}\text { Moderadamente bien } \\
\text { clasificado }\end{array}$ & $\begin{array}{l}\text { Negativa } \\
\text { Simétrica }\end{array}$ & Leptocúrtica & Unimodales & Sigmoidales \\
\hline $\begin{array}{l}\mathrm{n}-0.93 / \\
+2.99\end{array}$ & - & - & - & \multicolumn{6}{|c|}{ Relleno de origen antrópico } \\
\hline
\end{tabular}


clastos se disponen en 2 ó 3 hileras superpuestas, una al lado de la otra (a veces ligeramente imbricadas) sin ningún tipo de argamasa, configurando una rampa de suave pendiente orientada hacia el canal actual (Figuras 3A y D).

La primera se localizaba en el sector septentrional de la parcela y estaba constituida por bloques de hasta $124 \mathrm{~cm}$. Aunque había sido parcialmente destruida por las obras de vaciado del solar, pudimos analizar un tramo de $20 \mathrm{~m}$, constatando que estaba compuesta por 3 hiladas de cantos y bloques superpuestos (entre 20 y $65 \mathrm{~cm}$ de eje), entre los que se observaba una pequeña cantidad de arena (infiltración posterior). En algunos puntos, los cantos estaban levantados, ya que entre ellos habían circulado flujos acuosos que habían depositado lentejones de arenas gruesas. En total, salvaba un desnivel de $80 \mathrm{~cm}$ lo que se traduce en una pendiente media del $4 \%$ aunque esta inclinación no era homogénea, ya que en su tramo final se incurvaba bruscamente (pendiente superior al $8 \%$ ) concluyendo mediante un gran bloque de $124 \mathrm{~cm}$. La segunda es mucho más larga ya que atraviesa completamente la parcela prolongándose por debajo de la acera actual (Figura 3D). Topográficamente se sitúa $30 \mathrm{~cm}$ por encima de la anterior y presenta una pendiente sensiblemente inferior (en torno al $1.5 \%$ ). Está compuesta por 2 hiladas de cantos y bloques, sin argamasa, colocados uno al lado del otro (la anchura observada parcialmente oscila en torno a los $100 \mathrm{~cm}$ ). Algunos de los clastos presentan incrustaciones de conchas (permanecen pegadas) lo que nos ha permitido establecer su edad, situándose ésta en torno al $4710 \pm 30 \mathrm{BP}$ (4945-4650 cal. BP) (Beta-407176) (Tablas 1 y 2; Figura 2).

\subsubsection{UNIDAD ARENOSA (-5.43 A $-4.83 \mathrm{~m})$}

Encima de las rampas se desarrollan diversas acumulaciones arenosas de características granulométricas contrastadas. En algunos puntos observamos una serie de depósitos groseramente lenticulares, formados por arena con algunos tramos discontinuos arcillosos de tamaño centimétrico (mud-drapes) y diversos macro-restos vegetales, así como niveles centi-decimétricos de color blanquecino, compuestos por conchuela triturada, que están parcialmente cementados. Presentan estructuras en espina de pescado en la parte inferior y estratificación cruzada de bajo ángulo en la parte alta. La fracción gruesa disminuye de muro a techo, pasando del 58 al $8.5 \%$. Está constituida por gravas de arenisca, esquisto, caliza y cuarzo, con distintos grados de redondez, junto con fragmentos de Mytilus galloprovincialis, Cerastoderma edule, Scrobicularia plana y Ostrea edulis (aumentan hacia el techo del nivel), no observándose huellas de transporte en las conchas. Son especies eurihalinas que toleran fuertes variaciones en la salinidad. La fracción fina es claramente arenosa (> $98.8 \%$ ) predominando las arenas medias (excepto en la base dónde predominan las gruesas) aunque las gruesas también están bien representadas. Las dataciones mediante carbono-14 arrojan una edad de $2810 \pm 30 \mathrm{BP}$ (2970-2850 cal. BP) (Beta-407190) (Tablas 1 y 2; Figura 2).

\subsubsection{UNIDAD ARENOSA CON GRAVAS (-4.83 A -2.83 m)}

Es un nivel arenoso de $200 \mathrm{~cm}$ de potencia que en algunos puntos llega a solaparse parcialmente con el nivel anterior lo que nos indica un desmantelamiento parcial del nivel subyacente. La fracción gruesa varía de muro a techo, con porcentajes que oscilan entre el 25 y el $58 \%$ en la base y menos del $13 \%$ en el resto del tramo (a techo vuelve a elevarse hasta situarse en el $23 \%$ del total analizado). En todos los casos está constituida por gravas y cantos (centilo: $5.8 \mathrm{~cm}$ ) de cuarcita, cuarzo lechoso, arenisca y caliza, junto con algunas conchas de Mytilus galloprovincialis, Scrobicularia plana y Cerastoderma edule, así como macrorrestos vegetales. Los clastos presentan diversos grados de redondez dependiendo de la litología: las calizas y areniscas están sumamente rodadas mientras que los cuarzos apenas están subredondeados.

En la parte alta del nivel se han recogido diversos fragmentos rodados de ladrillo (de hasta $5.6 \mathrm{~cm}$ de eje mayor), así como numerosos fragmentos de madera, aunque estos últimos se distribuyen irregularmente a lo largo del perfil. No se han encontrado evidencias de manipulación humana, ni parece que forman parte de ningún tipo de estruc- 
tura, por lo que creemos que su sedimentación se ha producido en condiciones naturales. Los macro-restos vegetales analizados formaban parte de troncos de grandes dimensiones y se han identificado como Quercus subgénero Quercus. Este taxón incluye todos los Quercus de hoja caducifolia y marcestente que en la actualidad se desarrollan en el País Vasco (Quercus petraea, Quercus robur, Quercus humilis, Quercus faginea y Quercus pirenaica) (Figura 3C). La fracción arenosa es claramente dominante, superando en todos los casos el $99 \%$. Granulométricamente se observa una alternancia de subniveles en los que predominan las arenas gruesas (entre un 44 y un $60 \%$ junto a otros en los que son dominantes las medias (entre un 47 y un $81 \%$ ). Se han efectuado 2 dataciones mediante carbono- 14 una a muro y otra a techo. La primera arroja una edad de $2770 \pm 30$ BP $(2950$ - 2785 cal. BP) (Beta405048), mientras que la segunda sitúa la cronología en torno al $1220 \pm 30 \mathrm{BP}(1190-1065 \mathrm{cal}$. BP $)$ (Beta-405041) (Tablas 1 y 2; Figura 2).

\subsubsection{UNIDAD SUPERIOR DE ARENAS (-2.83 A -0.93 m)}

Tiene una potencia de $1.9 \mathrm{~m}$. En la base el sedimento se dispone masivo, mientras que en la parte alta se observa laminación plano-paralela. La fracción gruesa apenas representa el 1.1 \% del total analizado y está constituida por fragmentos de ladrillo y teja, junto con algunos restos metálicos (muy alterados) y conchas (Cerastoderma edule, Scrobicularia plana, Tellina fabula, Haliotis tuberculata, Mytilus galloprovincialis, Donax vittatus...). Las arenas representan más del $98 \%$ del total de finos analizado, predominando las arenas medias $(>55 \%) \mathrm{y}$, en menor medida, las finas. Su edad es posterior al $1220 \pm 30$ BP (1190-1065 cal. BP) (Tabla 2; Figura 2).

\subsubsection{RELLENO ANTRÓPICO (-0.93 A 2.37/2.99 m)}

Está constituido por restos de hormigón, tejas, madera y escombros en general (Figura 2).

\subsection{INTERPRETAGIÓN DE LOS SEDIMENTOS}

A tenor de las características geomorfológicas, sedimentológicas y faunísticas de los materiales in- vestigados, junto con las dataciones radiométricas obtenidas a lo largo del perfil estudiado, podemos diferenciar dos sucesiones deposicionales de composición y cronología contrastada. A su vez, dentro de cada una de estas sucesiones se individualizan diversas unidades asociadas a distintos ambientes sedimentarios.

La sucesión basal es Pleistocena (> $43500 \mathrm{BP}$ ), pudiendo identificarse 3 unidades de características diferenciadas. La unidad a (la más antigua) está compuesta por sedimentos limo-arenosos sin gruesos y con abundantes macro-restos vegetales dispersos en el nivel. Sus características granulométricas nos indican que estamos ante un sedimento homométrico, cuya sedimentación se produjo en condiciones de baja energía, con un claro predominio de la decantación sobre el lavado, siendo los flujos tractivos de escasa entidad. La ausencia de conchas y la presencia de lechos de hojas y de otros restos vegetales, junto con el elevado porcentaje de materia orgánica, sugieren que estamos ante una zona palustre de agua dulce (tipo marsh) desarrollada presumiblemente en condiciones de biostasia. Eventualmente, hasta este ambiente restrictivo llegaban aportes fluviales o fluvio-torrenciales responsables de la sedimentación de la fracción arenosa, compuesta casi exclusivamente por granos de cuarzo poco rodados. La ausencia de otros componentes mineralógicos, junto con las características morfoscópicas de la fracción arena, nos permiten descartar al Río Urumea como responsable de su depósito. Cronológicamente sólo sabemos que su formación se produjo hace más de 43500 años BP, pudiendo adscribirse a alguna fase interglaciar o interestadial Pleistocena (Tabla 3). Sobre este depósito se desarrolla la unidad b, compuesta por sedimentos heterométricos, heterolíticos y polimícticos. Son materiales poco evolucionados cuya sedimentación se produjo en condiciones forzadas al ponerse en contacto flujos de signo contrario, mezclándose dos subpoblaciones de características distintas; una, constituida por arenas gruesas transportadas en el seno de corrientes tractivas enérgicas y otra, más fina, movilizada por un medio distinto y/o en condiciones menos enér- 
gicas. La presencia de restos bioclásticos indica que uno de los medios era, cuando menos salobre, apuntando hacia un depósito canaliforme de tipo fluvio-estuarino afectado por procesos de flujo/reflujo. Durante la bajamar predominaba la dinámica fluvial, retrabajándose (y mezclándose con otros aportes) el sedimento durante la pleamar. Aunque desconocemos la localización del nivel del mar en estos momentos, éste debió situarse en una posición no muy diferente de la actual o a lo sumo una decena de metros por debajo. Todo ello permite descartar las fases más frías del Pleistoceno, ya que en esos momentos la línea de costa estaba muy alejada de su posición actual ( $>43500 \mathrm{BP}$ ), lo que nos induce a pensar que su edad puede ser Eemiense, tal y como se ha observado en otras acumulaciones del litoral cantábrico (Mary, 1979; Edeso-Fito, 1990; Cearreta et al., 1992; Edeso-Fito, 1992, 1994; Edeso-Fito y Mujika-Alustiza, 2005; Mujika-Alustiza y Edeso-Fito, 2011; Tabla 3).

Aunque no se ha podido determinar la continuidad estratigráfica vertical de la acumulación que acabamos de describir, existe una tercera unidad pleistocena (unidad c) situada, desde un punto de vista topográfico, por encima de la acumulación anterior, aunque en este caso, dicha unidad se apoya directamente sobre el sustrato rocoso subyacente (Figura 2). Es un sedimento limo-arenoso/ areno-limoso que contiene abundantes gravas así como numerosos restos bioclásticos y macro-restos vegetales carbonizados, vitrificados y muy refringentes. Se define como una facies heterométrica y heterolítica, constituida por una mezcla de materiales de origen local (o a lo sumo del entorno próximo), restos de malacofauna (bivalvos y gasterópodos) sin huellas de transporte y materiales finos poco evolucionados, cuya sedimentación se produjo en condiciones semiforzadas (al "colisionar" flujos de distintas direcciones), predominando la decantación sobre el lavado al ser retrabajado el sedimento por corrientes tractivas. Todos estos parámetros nos indican que estamos ante una mezcla de materiales procedentes de la alteración del sustrato, que se combinan con aportes estuarinos depositados en un ambiente marginal de salinidad normal (dominio fluvio-estuarino), y con otros vinculados a descargas fluviales. Las dataciones efectuadas señalan que su edad es Pleistocena ( $>$ $43500 \mathrm{BP}$ ) coincidiendo con alguna fase interglaciar en la que el nivel marino se situó en una posición similar (o algo más bajo) a la que ocupa en la actualidad (Tabla 3).

El relleno Holoceno presenta diversas unidades sedimentarias que reflejan, por un lado, la compleja variedad de medios existentes en esos ámbitos, y por otro, las variaciones experimentadas por el nivel del mar a lo largo del período considerado. Además, y teniendo en cuenta la posición de la zona investigada respecto a la línea de costa original, podemos reseñar que este ámbito forma parte del dominio marino-estuárico, aunque en una localización marginal respecto a los canales principales, lo que se refleja, tanto en la dinámica del medio como en las facies sedimentarias.

Sobre el conjunto Pleistoceno (o directamente sobre el sustrato rocoso) se desarrolla una unidad arenosa (unidad d) depositada en condiciones semiforzadas (predominio de la decantación sobre el lavado) en un ambiente poco agitado, no observándose remociones postdeposicionales, ni fluctuaciones energéticas significativas. Todos estos datos, junto con la presencia de abundantes restos bioclásticos, típicos de fondos blandos ricos en materia orgánica y de salinidad normal, nos indican que estamos ante un depósito submareal (en posición marginal respecto a los canales principales), formado en condiciones transgresivas o una vez estabilizado el nivel del mar tras la elevación flandriense (Figura 3E). Su edad supera los $7040 \pm 30$ BP (7565-7390 cal. BP), tal y como lo demuestran las dataciones de los niveles suprayacentes, aunque no ha podido determinarse la edad exacta de la unidad d, pudiendo atribuirsele una cronología holocena en función de las características granulométricas y, sobre todo, del grado de conservación de la malacofauna, aunque evidentemente, no existe una certeza absoluta (Tabla 3).

Encima de este nivel se desarrollan dos unidades arenosas (unidades e y f) constituidas por una mezcla (mayoritaria) de restos bioclásticos con cuar- 
Tabla 3. Evolución del nivel del mar y posición relativa del nivel del mar

\begin{tabular}{|c|c|c|c|c|c|}
\hline Unidad & Ambiente & Edad & Fase & Altura estimada del nivel del mar & Síntesis evolutiva \\
\hline 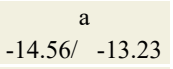 & Palustre & $>43500$ & $\begin{array}{l}\text { Nivel marino más bajo que el } \\
\text { actual }\end{array}$ & Desconocida & Continental \\
\hline $\begin{array}{c}\mathrm{b} \\
-13.23 /-12.88\end{array}$ & $\begin{array}{l}\text { Fluvio - } \\
\text { estuarino }\end{array}$ & $?$ & $\begin{array}{l}\text { Anegamiento del estuario } \\
\text { Pleistoceno }\end{array}$ & $\begin{array}{l}\text { Nivel marino situado, al menos, por } \\
\text { encima de los }-13 \mathrm{~m} \text {. }\end{array}$ & \multirow{2}{*}{ ¿Transgresión Eemiense? } \\
\hline $\begin{array}{c}\mathrm{c} \\
-12.88 /-12.28\end{array}$ & $\begin{array}{l}\text { Fluvio - } \\
\text { estuarino }\end{array}$ & $>43500$ & $\begin{array}{l}\text { Anegamiento del estuario } \\
\text { Pleistoceno }\end{array}$ & $\begin{array}{l}\text { Nivel marino situado, al menos, por } \\
\text { encima de los }-12 \mathrm{~m}\end{array}$ & \\
\hline$-12.28 /-11.18$ & Submareal & ? & Ascenso del nivel del mar & \multirow{4}{*}{$\begin{array}{l}\text { El nivel del mar, se situó, al menos a }-2 \mathrm{~m} \\
\text { respecto al actual. }\end{array}$} & \multirow{4}{*}{$\begin{array}{l}\text { Primera pulsación } \\
\text { transgresiva }\end{array}$} \\
\hline$-11.18 /-10.93$ & Submareal & ? & \multirow{2}{*}{ Estabilización del nivel del mar } & & \\
\hline$\frac{\mathrm{f}}{-10.93 /-10.83}$ & Submareal & $\begin{array}{c}7040 \pm 30 \mathrm{BP}(7565-7390 \\
\text { cal. BP })\end{array}$ & & & \\
\hline 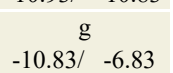 & $\begin{array}{l}\text { Submareal - } \\
\text { Intermareal }\end{array}$ & $\begin{array}{c}5910 \pm 30 \mathrm{BP}(6790-6665 \\
\text { cal. BP })\end{array}$ & Ascenso del nivel del mar & & \\
\hline $\begin{array}{c}\mathrm{h} \\
-6.83 /-6.78\end{array}$ & Intermareal & $\begin{array}{c}5200 \pm 30 \mathrm{BP}(5995-5910 \\
\text { cal. BP })\end{array}$ & Descenso del nivel del mar & \multirow{2}{*}{$\begin{array}{l}\text { No determinada, aunque no muy distinta } \\
\text { de la actual. }\end{array}$} & Primera pulsación regresiva \\
\hline$-6.78 / \quad-5.63$ & Intermareal & $?$ & Ascenso del nivel del mar & & $\begin{array}{l}\text { Segunda pulsación } \\
\text { transgresiva }\end{array}$ \\
\hline $\begin{array}{c}\mathrm{j} \\
-5.63 /-5.43\end{array}$ & Intermareal & $\begin{array}{c}4710 \pm 30 \mathrm{BP}(4945-4650 \\
\text { cal. BP })\end{array}$ & Descenso del nivel del mar & $\begin{array}{c}\text { Al menos } 2 \mathrm{~m} \text { por debajo de la posición } \\
\text { que ocupa en la actualidad }\end{array}$ & $\begin{array}{l}\text { Segunda pulsación } \\
\text { regresiva }\end{array}$ \\
\hline $\begin{array}{c}\mathrm{k} \\
-5.43 /-4.83\end{array}$ & Intermareal & $\begin{array}{c}2810 \pm 30 \mathrm{BP}(2970-2850 \\
\text { cal. BP })\end{array}$ & Ascenso del nivel del mar & Posición similar a la actual & \multirow{4}{*}{$\begin{array}{c}\text { Tercera pulsación } \\
\text { transgresiva y estabilización } \\
\text { - Oscilación en época } \\
\text { histórica }\end{array}$} \\
\hline $\begin{array}{c}1 \\
-4.83 / \quad-2.83\end{array}$ & Intermareal & $\begin{array}{c}2770 \pm 30 \mathrm{BP}(2950-2785 \\
\text { cal. BP) } 1220 \pm 30 \mathrm{BP}(1190- \\
1065 \text { cal. BP })\end{array}$ & Estabilización del nivel del mar & $\begin{array}{l}\text { Posición similar a la actual o incluso } 0.5 / 1 \\
\text { m por encima. }\end{array}$ & \\
\hline$\frac{\mathrm{m}}{-2.83 / \quad-0.93}$ & Intermareal & $?$ & Oscilación del nivel del mar & Posición actual & \\
\hline$\frac{\mathrm{n}}{-0.93 /+2.99}$ & Intermareal & Siglo XX & Actual & Posición actual & \\
\hline
\end{tabular}

zos subangulosos. La arena gruesa y media está constituida por caparazones completos de gasterópodos y bivalvos, depositados in situ o a lo sumo procedentes del entorno inmediato (no presentan huellas de rodamiento). El origen de los cuarzos es marino ya que sus rasgos morfoscópicos permiten descartar su origen fluvial (Edeso-Fito, 1990). La ausencia de fragmentos de esquisto, tanto en la fracción gruesa como en la arenosa, muy abundantes en los arrastres fluviales actuales y pasados del Urumea, apuntan en esta misma dirección. La mezcla de ambas fracciones explica los valores granulométricos del sedimento. Teniendo en cuenta todos estos rasgos, creemos que su depósito se produjo en una zona de aguas poco agitadas, que no se veían apenas afectadas por la acción de las olas y de las corrientes mareales. Se trata, probablemente, de un ambiente submareal muy restringido, pero de salinidad normal. Las dataciones radiométricas sitúan su sedimentación en torno al $7040 \pm 30$ BP (7565-7390 cal. BP) (Tabla 3).
Sobre estos materiales se desarrolla una unidad arenosa (unidad g) que presenta diversas estructuras sedimentarias, así como variaciones granulométricas y composicionales a lo largo del perfil. Pueden diferenciarse dos subunidades distintas: la inferior, cuya sedimentación ha sido libre por exceso de carga en un ambiente enérgico en el que predominaba el lavado sobre la decantación y otra superior que muestra una alternancia de lechos con características granulométricas diferentes. En este segundo caso, la sedimentación fue semiforzada en un medio agitado en el que el lavado también predominaba sobre la decantación. Estas características son similares a las que presenta el shoreface de las playas actuales (Edeso-Fito, 1990; Lopetegi-Galarraga, 2011). Son barras arenosas submareales primero e intermareales después (la somerización del medio se produce por colmatación, aunque en la subunidad superior se aprecian signos vinculados al inicio de una fase regresiva) que migran hacia tierra durante la fase de trans- 


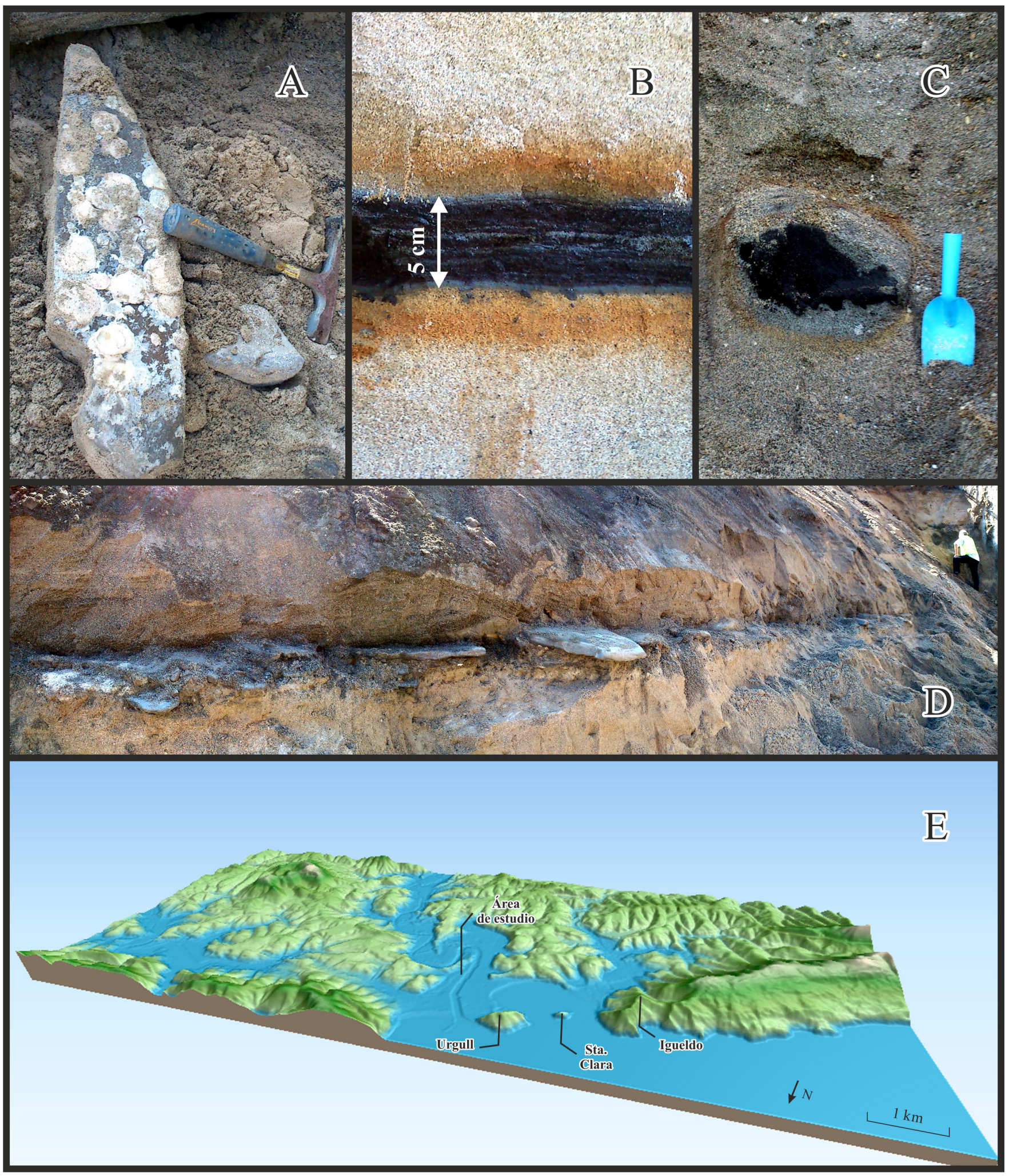

Figura 3 Imágenes del depósito analizado y bloque diagrama. $\mathrm{A}=$ Bloque de la rampa con incrustaciones de conchas; $\mathrm{B}=\mathrm{Nivel}$ orgánico unidad $\mathrm{h} ; \mathrm{C}=$ Fragmento de madera encontrada en unidad I; $\mathrm{D}=$ Vista panorámica de la rampa; $\mathrm{E}=\mathrm{Bloque}$ diagrama que muestra el nivel máximo de inundación holocena durante la transgresión flandriense. 
gresión/estabilización marina. Las descargas fluviales no han desempeñado ningún papel significativo, ya que ni la morfoscopia ni la mineralogía de la fracción arenosa, muestran evidencias de aportes fluviales. Posiblemente, los canales fluviales y mareales se situaban alejados de la zona deposicional. A tenor de las dataciones efectuadas podemos determinar que su formación se produjo entre el $5910 \pm 30 \mathrm{BP}(6790-6665$ cal. BP $)$ y el $5200 \pm 30 \mathrm{BP}(5995-5910$ cal. BP). Es decir, en 775 años (utilizando las edades medias calibradas) se depositaron (al menos) $4 \mathrm{~m}$ de sedimento, lo que arroja una tasa media de $5.161 \mathrm{~mm}$ al año (Tabla $3)$.

La unidad descrita anteriormente presenta su techo erosionado y disectado por surcos fluviales y/o mareales (unidad h) en los que se han acumulado abundantes macro-restos vegetales (Figura 3B) que han sido datados en el $5200 \pm 30 \mathrm{BP}$ (5995-5910 cal. BP). Apuntan hacia un medio intermareal, cuyo techo se sitúa a tan sólo $-2.27 \mathrm{~m}$ respecto al nivel de la bajamar actual (Tabla 3).

Sobre ellos encontramos una unidad arenosa con estratificación en espina de pescado (unidad i), originada por el flujo y reflujo de la marea, que hacia el techo de la serie es sustituida por materiales que presentan estratificación cruzada planar. Las características granulométricas de estos materiales indican que estamos ante un sedimento homométrico, bien evolucionado, cuya sedimentación se produjo por exceso de carga en un ambiente marino sometido a bruscas modificaciones de flujo (intermareal). La parte superior está constituida también por un sedimento homométrico, relativamente bien clasificado (sedimentación libre por exceso de carga en la parte inferior y semiforzada en la superior) lo que parece apuntar hacia un medio intermareal del tipo barra. Entre el 5200 $\pm 30 \mathrm{BP}(5995-5910 \mathrm{cal}$. BP $)$ y el $4710 \pm 30 \mathrm{BP}$ (4945-4650 cal. BP) se depositaron $135 \mathrm{~cm}$ de sedimento, lo que arroja una tasa media de 1.28 $\mathrm{mm}$ /año (Tabla 3).

Sobre estos materiales se construyeron, en torno al $4710 \pm 30 \mathrm{BP}(4945-4650 \mathrm{cal}$. BP) dos rampas de cantos y bloques dispuestas transversalmente respecto al canal principal y que presumiblemente fueron utilizadas para introducir y extraer embarcaciones del estuario (unidad j). Sea cual sea su finalidad, con un nivel del mar similar al actual, ambas rampas estarían permanentemente sumergidas (entre 5.6 y $5.43 \mathrm{~m}$ durante la pleamar y entre 3.22 y 3.15 durante la pleamar media), por lo que hay que suponer que cuando se construyeron el nivel del mar debería de situarse, al menos, varios metros por debajo de su posición actual, lo que permitiría su uso, tanto durante la bajamar como en condiciones de marea media y pleamar (Tabla 3).

Encima de estas rampas se desarrollan diversas unidades arenosas, identificadas como barras lenticulares con estructura en espina de pescado (unidad k), conformadas en un medio intermareal en el que alternan las condiciones de flujo y reflujo. Sus características granulométricas nos indican que estamos ante un sedimento heterométrico, poco evolucionado, cuya sedimentación se produjo en condiciones forzadas o semiforzadas con un claro predominio del lavado sobre la decantación. La sedimentación tuvo lugar en un ambiente enérgico, claramente marino al principio y típicamente fluvio-estuarino después, apuntando hacia condiciones intermareales. Su edad se sitúa en torno al $2810 \pm 30$ BP (2970-2850 cal. BP) y señalan un nivel marino no muy diferente del actual, ya que su techo se sitúa tan sólo entre -0.87 y - 0.17 m por debajo de la bajamar actual (Tabla 3).

Esta acumulación deja paso a la unidad 1, definida como un nivel arenoso con gravas, macro-restos vegetales y evidencias antrópicas en su parte alta. Sus características granulométricas nos indican que estamos ante una superposición de barras fluviomareales que evolucionan desde condiciones francamente fluviales a otras claramente marinas. La fracción gruesa es heterométrica, heterolítica y polimíctica y está constituida por materiales procedentes del Macizo Paleozoico de Cinco Villas que han sido transportados por el Río Urumea. La fracción fina constituye un sedimento poco evolucionado cuyo depósito se produjo en condiciones forzadas o semiforzadas, predominando el lava- 
do sobre la decantación. Está constituida por dos subpoblaciones de origen distinto, una fluvial que ha sido parcialmente retrabajada en un ambiente estuarino por las olas y corrientes, y otra marina clasificada en un ambiente más enérgico, que ha sido transportada posteriormente, hasta su localización actual. La mezcla de ambas se produce en condiciones claramente estuarinas, estando el sedimento sometido a la acción de flujos fluviales, mareales y olas (lavado de finos). Estos materiales quedaban expuestos durante la bajamar, ya que su techo se sitúa ya entre +0.06 y +1.69 m por encima del nivel del mar actual (en bajamar) (Tabla 3). Su depósito se produjo entre el $2810 \pm 30 \mathrm{BP}$ (2950-2785 cal. BP) y el $1240 \pm 30$ BP (1190-1065 cal. $\mathrm{BP}$ ) en una fase transgresiva primero y de estabilización después.

Sobre estas barras fluvio-estuarinas se desarrolló un nivel arenoso (unidad m) con abundantes evidencias antrópicas. Su granulometría indica que estamos ante un sedimento homométrico, bien evolucionado y con características similares a las que presentan las barras y las zonas batidas por el oleaje (intermareal) de las playas actuales (Edeso-Fito, 1990; Lopetegi-Galarraga, 2011) y de la desembocadura del estuario. Su sedimentación tuvo lugar a partir del $1240 \pm 30 \mathrm{BP}(1190-1065$ cal. BP), prolongándose hasta el siglo XIX (unidad n), momento en el que la zona es rellenada y ocupada por el hombre (Rivas y Cendrero, 1992). Ambas unidades son claramente intermareales ya que se sitúan entre +1.69 y +3.63 m por encima del nivel alcanzado por la bajamar actual. $\mathrm{Su}$ techo sólo permanecía sumergido durante la pleamar (Tabla 3).

$\mathrm{El}$ análisis de la cartografía antigua pone de manifiesto que tanto la desembocadura, como la bahía y el puerto de Donostia-San Sebastián presentaban una importante acumulación arenosa ya en el siglo XVIII (Figura 4, Gómez-Piñeiro et al., 1994). Además, en la boca del estuario se habían forma- do dos barras arenosas submareales e intermareales que estrangulaban la boca del estuario (Figura 4), obligándole a desaguar a través de un estrecho canal localizado a la altura del actual puente de Santa Catalina (Figura 1). Es decir, a partir del siglo XVIII (probablemente mucho antes) estamos ante un estuario semi-cerrado, de tal manera que la continua adición de arena a las barras de cierre, determinaba su progradación hacia el mar, así como la formación de barreras intermareales que migran hacia tierra como deltas de flujo de marea. Durante este lapso temporal, las descargas fluviales no han dejado evidencias significativas.

\section{Síntesis evolutiva y discusión}

La zona investigada ha funcionado durante algunos momentos del Pleistoceno y el Holoceno como un estuario inundado de tipo ría (parcialmente protegido por las islas de Santa Clara y Urgull; Figura $1 \mathrm{C}$ ), dominado por mareas de rango mesomareal. Aunque desconocemos la paleogeografía exacta de la zona investigada, sabemos que el tómbolo arenoso sobre el que se asienta actualmente el centro urbano de San Sebastián no se ha formado hasta fechas recientes ${ }^{\mathrm{d}}$ (Figura 4; Gómez-Piñeiro et al., 1994; Edeso-Fito, 1990, 1991, 1999), y que el Río Urumea, - cuyo canal principal se situaba, al menos $40 \mathrm{~m}$ por debajo de su cota actual-, discurría a través de la avenida de la Libertad y de los arenales de San Martine, desembocando en la actual bahía de La Concha. A partir de este punto, dibujaba un paleovalle de trazado bastante rectilíneo, que discurría entre la isla de Santa Clara y la isla de Urgull (actualmente unida al continente mediante el tómbolo de San Sebastián; Figura 5). $\mathrm{Al}$ margen de estas consideraciones, hay que tener en cuenta que el espacio analizado se localiza en la parte final del estuario (dominio marino-estuarino) por lo que la dinámica del medio está dominada

\footnotetext{
d En 1150 ya se había consolidado, aunque quedaba sumergido durante las mareas vivas.

e Información obtenida a partir de diversos estudios geotécnicos realizados en las últimas décadas como consecuencia de la intensa urbanización acaecida en esta zona.
} 


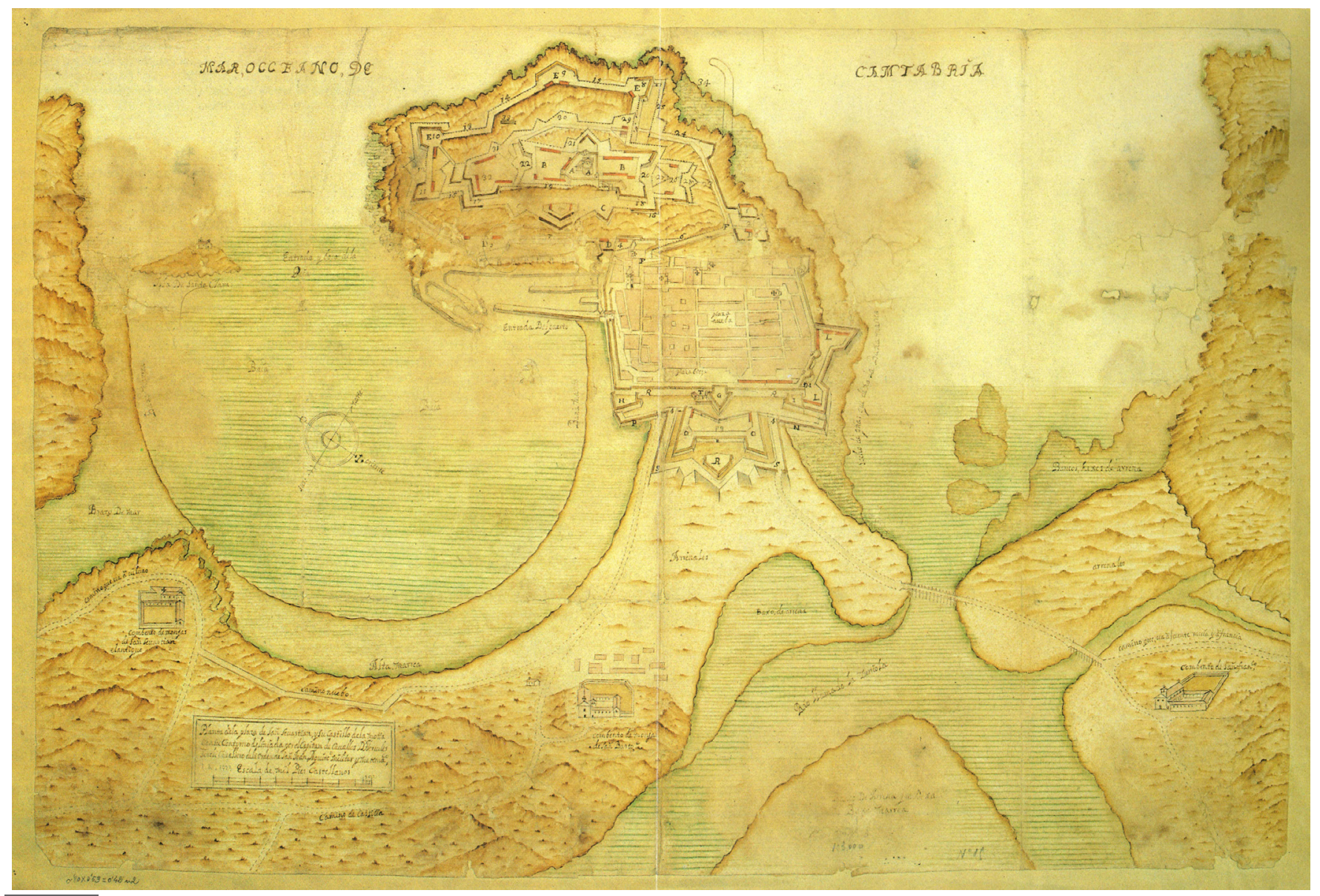

Figura 4 Antiguo mapa (s. XVIII) de Donostia - San Sebastián (Gómez-Piñeiro et al., 1994).

por las olas y corrientes mareales intensas, aunque la posición relativamente marginal del enclave respecto a los canales principales, matiza su importancia. Por si esto fuera poco, no hay que olvidar que a lo largo del Holoceno se suceden una serie de variaciones en el nivel del mar que modifican la línea de costa, así como los diversos procesos que intervienen en el modelado del entorno, sucediéndose tanto eventos deposicionales como erosivos. La edad de las unidades más profundas es Pleistocena, vinculándose, probablemente al Eemiense ya que su sedimentación se produjo en un ambiente marino (estuarino), lo que implica una fase transgresiva de inundación del paleovalle del Urumea. Estos episodios transgresivos únicamente se han producido durante las fases interglaciares, siendo la Eemiense la última acaecida antes de la actual Holocena. En el entorno regional del Mar
Cantábrico, encontramos depósitos Eemienses en el estuario del Bidasoa (Irún) (Edeso-Fito, 1992; Cearreta et al., 1992), en la semidepresión-estuario de Zarautz (Edeso-Fito, 1990, 1992), ambos localizados en el litoral guipuzcoano, en diversos puntos del litoral asturiano (Mary, 1979) y en la zona de Castro Urdiales, dentro del ámbito litoral cántabro (González-Amuchástegui et al., 2005).

Tras la deglaciación Wurmiense, iniciada hace 19000 años (Fleming et al., 1998; Bard et al., 2010), el nivel del mar experimentó una rápida elevación mediante una serie de pulsos transgresivos (Liu y Milliman, 2004; Blanchon et al., 2011a; Gornitz, 2013) separados entre sí por períodos de estabilidad e incluso de leve/moderado retroceso. Aunque no existe una curva absoluta de validez mundial e incluso las curvas regionales elaboradas en los últimos años presentan diversos interrogan- 


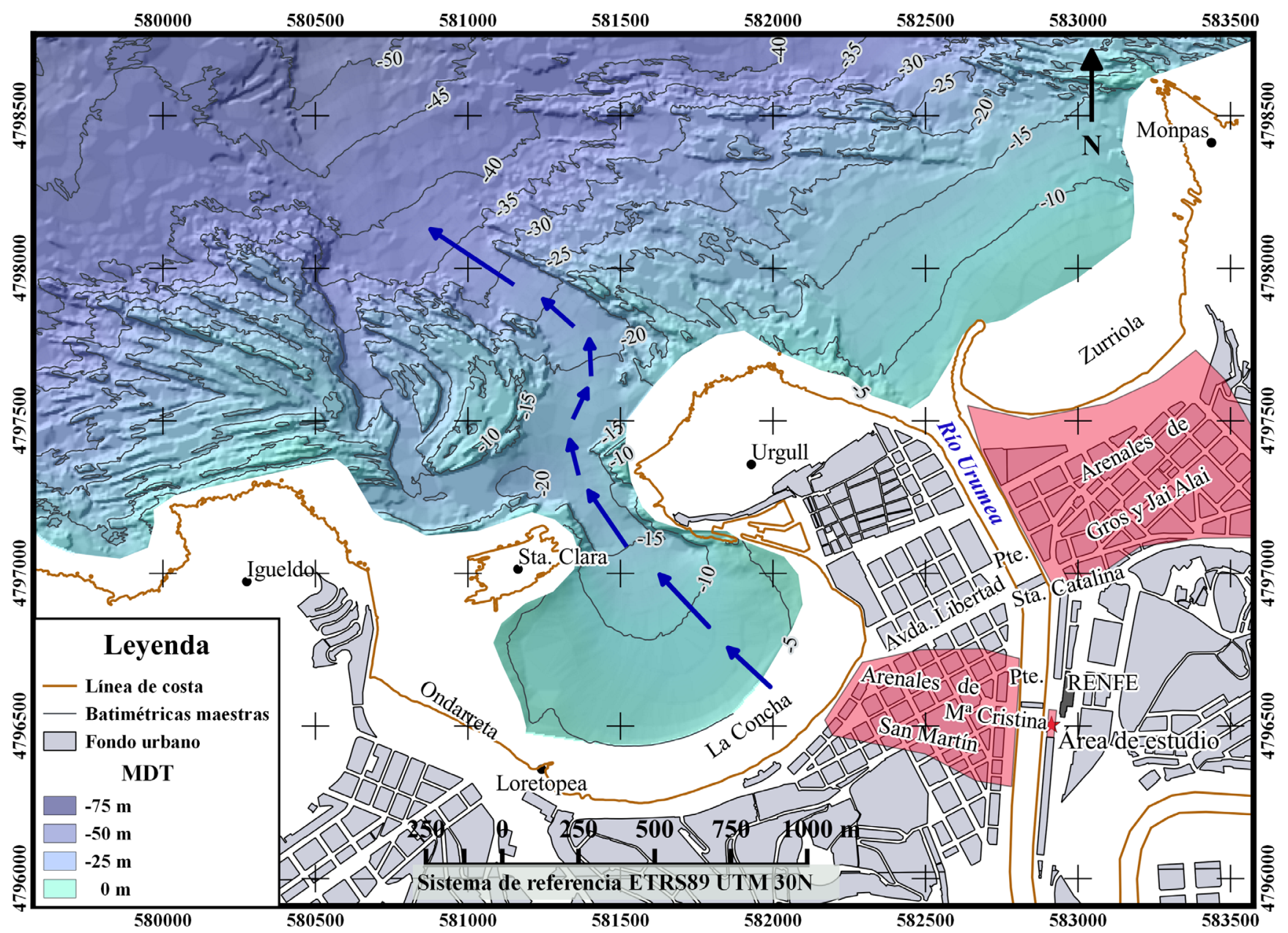

Figura 5 Mapa batimétrico de la costa adyacente a Donostia - San Sebastián a partir de datos batimétricos obtenidos de la infraestructura de datos espaciales del Gobierno Vasco (Geoportal - geoEuskadi, 2015). Obsérvese el canal que se abre entre la isla de Santa Clara y el monte Urgull, interpretado como el paleovalle del Río Urumea (flechas azules).

tes e incongruencias en función de factores locales o regionales y de los vacíos de información existente (González et al., 2004; Leorri y Cearreta, 2009; Alonso y Pagés, 2010; Leorri y Cearreta, 2012), podemos afirmar que los paleovalles fluviales cantábricos ya habían empezado a inundarse en el Younger Dryas (pulso MWP-1B) (Blanchon y Shaw, 1995; Bard et al., 2010; Blanchon et al., $2011 \mathrm{a}, 2011 \mathrm{~b}$ ) e incluso bastante antes en el caso de los estuarios más profundos (pulso MWP-1A), estimándose que en esos momentos la línea de costa se situaba en torno a los $-40 \mathrm{~m}$. Esta rápida elevación del nivel del mar se prolongó, de forma más o menos ininterrumpida, hasta el 7500/7600
BP mediante los pulsos MWP-1C y MWP-1D (Liu y Milliman, 2004; Gornitz, 2013).

Teniendo en cuenta la "escasa" profundidad del estuario del Urumea, es poco probable que el influjo marino se dejase sentir con anterioridad al 8000 BP (pulso secundario mwp-1c) (Liu y Milliman, 2004). Los vestigios sedimentarios correspondientes a esta primera pulsación transgresiva son muy escasos en el estuario del Urumea y están constituidos por arenas finas probablemente relacionadas con un delta submareal de flujo y reflujo o con una llanura arenosa y por una serie de facies constituidas casi exclusivamente por restos bioclásticos fechados en torno al $7040 \pm 30$ BP (7565-7390 
cal. BP), apuntando el techo de estos sedimentos ya hacia condiciones de estabilidad. Esta edad es sensiblemente más joven que otras obtenidas en estuarios del Mar Cantábrico. En la semidepresión-estuario de Zarauz, situado a $15 \mathrm{~km}$ al oeste de San Sebastián, la fecha más antigua obtenida, si bien a una profundidad algo más baja que la cota inferior de este trabajo, sitúa esta primera fase transgresiva en el $7855 \pm 42 \mathrm{BP}(8780-8830$ cal. BP) (Edeso-Fito y Mujika-Alustiza, 2005; Mujika-Alustiza y Edeso-Fito, 2011). Estas primeras huellas también se remontan a edades más antiguas en otros estuarios de la costa cantábrica vasca situados al oeste de San Sebastián, como es el caso de los estuarios de Bilbao (8202-7927 cal. BP), Urdaibai (8700-8380 cal. BP) y Deba $(91$ 10-8800 cal. BP; Leorri et al., 2012). Tras esta fase de estabilización, se reanuda la elevación del nivel marino detectándose un incremento de la dinámica energética, lo que se refleja en una unidad arenosa que denota condiciones deposicionales muy enérgicas en la base (submareales en zona de batida) y algo menos enérgicas en el tramo alto. El paso de la sucesión submareal-intermareal se produce por colmatación y disminución de la lámina de agua (inicio de la regresión a techo), lo que se traduce en un descenso de la profundidad. Esta fase ya había concluido en el $5200 \pm 30$ BP (5995-5910 cal. BP). Esta unidad finaliza bruscamente mediante una superficie erosiva en la que se acumulan abundantes macrorrestos vegetales datados en el $5200 \pm 30$ BP (5995-5910 cal. BP). Apuntan hacia una pulsión regresiva, situándose el nivel del mar varios metros por debajo de su posición actual, ya que el techo de la acumulación se localiza a -2.22 m por debajo del nivel de bajamar y a $-4.5 \mathrm{~m}$ respecto al intermareal actual. Con posterioridad, entre el $5200 \pm 30 \mathrm{BP}(5995-5910 \mathrm{cal}$. BP $)$ y el $4710 \pm$ 30 BP (4945-4650 cal. BP) se constata una nueva elevación del nivel del mar, formándose sendas barras intermareales de flujo y reflujo.

Sobre la última de estas barras se construyen dos rampas cuya finalidad se desconoce. Sabemos que ya existían en el $4710 \pm 30$ BP (4945-4650 cal. $\mathrm{BP})$, lo que apunta hacia una fase regresiva con un nivel marino sensiblemente inferior al actual, ya que de lo contrario dichas rampas serían inoperativas al quedar cubiertas por una lámina de agua de más de $2 \mathrm{~m}$ de altura durante la mayor parte de la marea. Su construcción implica además que las condiciones del medio habían cambiado, pasando de una situación de alta energía (responsable del depósito de las barras arenosas subyacentes) a otra mucho más tranquila, que permitía la conservación de las rampas. Todo ello apunta hacia una fase regresiva, con descenso del nivel del mar, pudiendo incluso quedar emergidas las rampas durante la bajamar y sumergidas durante la pleamar, tal y como lo demuestra la presencia de malacofauna en posición de vida pegada a los cantos (con ambas valvas).

No existen evidencias sedimentarias de lo acaecido entre la construcción de la rampa y el $2810 \pm$ 30 BP (2970-2785 cal. BP), por lo que es probable que tras la regresión reseñada anteriormente, el nivel del mar se estabilizó, lo que permitió el mantenimiento de las rampas. Son numerosas las evidencias existentes a lo largo del litoral cantábrico que apuntan en esta misma dirección. Podemos citar, entre otras muchas, las del estuario de Zarautz, las de la turbera de Trengandín en Cantabria o las de la ría de Arousa en Galicia. La horquilla cronológica obtenida, sitúa esta fase entre el $6010 \pm 90 \mathrm{BP}(6960-6720 \mathrm{cal}$. BP $)$ y el $2740 \pm 90 \mathrm{BP}(3078-2724$ cal. BP) en el primer caso (Edeso-Fito, 1991, 1994; Edeso-Fito y Mujika-Alustiza, 2005; Mujika-Alustiza y Edeso-Fito, 2011), entre el $4070 \pm 100(4654-4763$ cal. BP) y el $2890 \pm 70$ (2939-3150 cal. BP) (Cearreta, 1993; Salas et al., 1996) en el segundo y en torno al 4020 \pm 40 BP (4175-3900 cal. BP) en el tercero (Rey y Vilaseco, 2012). Asimismo, los datos recogidos en los estuarios de Bilbao, Urdaibai y Deba (Costa vasca) también apuntan hacia la posible existencia de una fase de descenso del nivel del mar entre el 4000 y el 2000 cal. BP (Leorri et al., 2012). Estas fechas coinciden grosso modo con las obtenidas en la zona de estudio y apuntan hacia un nivel marino situado, al menos, -2/-3 $\mathrm{m}$ por debajo de su posición actual, aunque no existe unanimidad a la 
hora de fijar la línea de costa, admitiéndose una horquilla que fluctúa entre -1 y -5 m (Alonso y Pagés, 2010).

A partir del 3000/3100 BP tiene lugar una nueva pulsación transgresiva (Edeso-Fito, 1991; 1994; Leorri et al., 2009; Alonso y Pagés, 2010) localizándose el nivel del mar en una posición similar o incluso ligeramente por encima de la que ocupa en la actualidad. La rampa es enterrada a partir del $2810 \pm 30$ BP (2970-2785 cal. BP) por sedimentos marinos primero, y fluvio-mareales después, lo que concuerda con lo observado en otros ámbitos cercanos. En la semidepresión-estuario de Zarautz se ha datado un nivel marino cuyo techo se localiza $0.5 \mathrm{~m}$ por encima del máximo nivel alcanzado por la pleamar actual. La edad de esta acumulación es posterior al $4920 \pm 100$ BP (5760-5580 cal. BP; Edeso-Fito, 1990, 1991, 1994). Esta situación se mantiene bastante estable hasta épocas históricas, momento en el que tiene lugar una pequeña elevación marina que sitúa la línea de costa por encima de su posición actual (Mary, 1979; Flor, 1983; Edeso-Fito, 1991; Vilas et al., 1991; Edeso-Fito, 1992; Mujika-Alustiza y Edeso-Fito, 2011), aunque la horquilla cronológica obtenida por los diversos investigadores fluctúa, en fechas calibradas, entre el 420 BC-170 AG y el 540-690 AC. Es decir, entre finales del primer milenio antes de Cristo y la Alta Edad Media, el nivel del mar se elevó entre 1 y 2 m por encima de su posición actual (Edeso-Fito et al., 2014; Lopetegi-Galarraga et al., 2014). En el estuario del Urumea, esta pequeña oscilación se refleja en los depósitos marinos (unidad m) situados por encima de las barras fluviomareales que entierran las rampas.

Ya en época histórica, se configura el tómbolo de San Sebastián (Figura 4), tal y como lo ratifican diversos documentos que señalan que en el 1150 todavía quedaba sumergido durante la pleamar, se forman las barras arenosas que cierran parcialmente el estuario y alcanzan su máximo desarrollo los arenales de Gros, San Martín y Jai-Alai. A mediados del siglo XIX estos espacios son ocupados y rellenados por el hombre instalándose diversas infraestructuras sobre ellos.

\section{Conclusiones}

A lo largo del Cuaternario se han sucedido numerosas fases frías junto a otras cálidas y/o templadas que han provocado importantes variaciones del nivel del mar, sucediéndose las fases de sumersión junto a otras de emersión de grandes porciones de la plataforma continental. Las evidencias encontradas en el entorno del Mar Cantábrico son escasas y quedan relegadas, en gran medida, a las zonas estuarinas y a diversos enclaves localizados a lo largo del litoral.

A partir del estudio detallado de los materiales que rellenan el solar investigado, se han observado dos sucesiones sedimentarias, una muy fragmentaria, probablemente vinculada a la transgresión Eemiense. Se trataría de sedimentos depositados en un ambiente marino (estuarino), -sobre otros continentales de tipo palustre-, lo que implica una fase transgresiva que inundó el paleovalle del Urumea. Por encima, se describe una estratigrafía holocena típica de colmatación de un ambiente marino-estuárico, apoyándose o bien sobre las unidades Pleistocenas o directamente sobre el sustrato rocoso subyacente. Son materiales submareales y/o intermareales, típicos de ambientes de alta salinidad, pudiendo reconocerse depósitos fluvio-estuarinos, barras, llanuras arenosas/deltas submareales, etc. La información referida al Holoceno es mucho más abundante, lo que nos ha permitido establecer la evolución sedimentaria de esta zona del estuario. Estos datos permiten definir con mayor precisión las características generales del ascenso del nivel de mar acontecido en el Mar Cantábrico desde finales de la deglaciación Wurmiense. La sucesión holocena se extiende desde el $7040 \pm 30$ BP (7565-7390 cal. BP) hasta nuestros días, aunque si atribuimos las unidades basales (d y e) al Holoceno podemos retrasar aún más la fecha de inundación del estuario. Se han podido establecer 
3 fases transgresivas (interrumpidas por períodos de estabilización), separadas por dos fases regresivas relativamente cortas. Inicialmente, el primitivo valle fluvial es anegado por el mar (primera pulsación transgresiva) instaurándose unas condiciones marino-estuáricas con sedimentación de materiales, fundamentalmente arenosos. A medida que el nivel del mar se eleva, el estuario sufre una activa agradación que fue colmatando el espacio investigado. Es una elevación relativamente rápida, interrumpida por breves episodios de estabilización. En torno al $5200 \pm 30 \mathrm{BP}(5995-5910 \mathrm{cal}$. BP) tiene lugar una pequeña regresión marina, desmantelándose parcialmente el sedimento y depositándose lechos de hojas en el interior de diversos surcos erosivos situados a techo de la unidad g. Una segunda pulsación transgresiva, continua aportando sedimentos arenosos, desarrollándose dicha fase con posterioridad al $5200 \pm 30 \mathrm{BP}(5995-5910$ cal. BP), habiendo concluido ya en el $4710 \pm 30$ BP (4945-4650 cal. BP). En torno a esa fecha, se produce la segunda fase regresiva, lo que permite la ocupación de estos espacios y la construcción de dos rampas cuya finalidad exacta desconocemos. Por último, en torno al 3000 se constata una nueva pulsación transgresiva que entierra las rampas, imponiendo condiciones marino-estuáricas primero y fluvio-estuarinas después. En el techo de las acumulaciones se constatan abundantes restos antrópicos transportados y movilizados por los diversos flujos que afectan a esta zona.

Existen evidencias que apuntan hacia una oscilación transgresiva en épocas históricas, aunque no son tan claras como las observadas en otros ámbitos geográficos próximos. Por último, el estuario se colmata casi totalmente de aportes arenosos y otros de origen antrópico adquiriendo su aspecto actual.

\section{Agradecimientos}

Este manuscrito ha sido mejorado gracias a las sugerencias y aportaciones de dos revisores. Ex- tendemos nuestro más sincero agradecimiento al Excmo. Ayuntamiento de Donostia - San Sebastián y al consorcio de empresas (UTE Intermodal Donosti) por la disponibilidad y comprensión demostrada a la hora de acceder a la obra a pesar de las inevitables molestias generadas, así como a la Diputación de Gipuzkoa por la financiación de algunas de las dataciones aquí presentadas.

El estudio se ha desarrollado en el marco del Proyecto HAR2011-26956 (Ministerio de Ciencia y Competitividad) y del Grupo de Investigación del Sistema Universitario Vasco IT-622-13 que han financiado algunas de las dataciones aquí presentadas.

\section{Referencias}

Alonso, A., Pagés, J.L., 2010, Evolución del nivel del mar durante el holoceno en el noroeste de la Península Ibérica: Sociedad Geológica de España, 23, 157-167.

Bailey, R.G., 1995, Ecosystem Geography: New York, Springer-Verlag, 204 p.

Bard, E., Hamelin, B., Delanghe-Sabatier, D., 2010, Deglacial Meltwater Pulse 1B and Younger Dryas Sea Levels revisited with Boreholes at Tahiti: Science, 327, 1235-1237.

Barnolas, A., Pulajte, V., 2004, La Cordillera Pirenaica, en Vera, J.A. (ed.), Geología de España: Madrid, SGE-IGME, 233-241.

Blanchon, P., 201 la, Meltwater Pulses, en Hopley, D. (ed.), Encyclopedia of Modern Coral Reefs: Structure, form and process: New York, Springer-Verlag, 683-690.

Blanchon, P., 2011 b, Backstepping, en Hopley, D. (ed.), Encyclopedia of Modern Coral Reefs: Structure, form and process: New York, Springer-Verlag, 77-84.

Blanchon, P., Shaw, J., 1995, Reef drowning during the last deglaciation: evidence for catastrophic sea-level rise and icesheet collapse: Geology, 23, 4-8. 
Blanco-Chao, B., Costa, M., Martinez, A., Pérez Alberti, A., Vázquez, M., 2002, Holocene evolution on Galician coast (NW Spain): an example of paraglacial dynamics: Quaternary International, 93-94, 149-159.

Blott, J., Pye, K., 2001, Gradistat: a grain size distribution and statistics package for the analysis of unconsolidated sediments: Earth Surface Processes and Landforms, 26, 1237-1248.

Cailleux, A., Tricart, J., 1961, Initiation à l'étude des sables et des galets: Annales de Géographie, 71, 310-313.

Cearreta, A., 1993, Palaeoenvironmental interpretation of Holocene coastal sequences in the southern bay of Biscay: Geologische Rundschau, 83, 234-240.

Cearreta, A., Edeso-Fito, J.M., Ugarte, F.M., 1992, Cambios del nivel del mar durante el Cuaternario reciente en el Golfo de Bizkaia, en The late Quaternary in the Western Pyrenean region: Bilbao, España, UPVEHU, 57-94.

Davies, J.L., 1964, A morphogenetic approach to world shorelines: Zeitschrift fur Geomorphologie, 8, 127-142.

Edeso-Fito, J.M., 1990, Geomorfología fluvial y litoral del extremo oriental de Gipuzkoa: Zaragoza, España, Universidad de Zaragoza, tesis doctoral (inédita), 666 p.

Edeso-Fito, J.M., 1991, Variaciones del nivel del mar en el País Vasco durante el Holoceno: Boletín de la Asociación de Geógrafos Españoles, 13, 21-44.

Edeso-Fito, J.M., 1992, Variaciones del nivel del mar durante el Pleistoceno Medio (extremo oriental de Guipúzcoa, País Vasco): Lurralde, 15, 63-106.

Edeso-Fito, J.M., 1994, El relleno Holoceno de la depresión de Zarautz: Lurralde, 17, 115-152.

Edeso-Fito.J.M., 1999, Geología y Geomorfología, en Gómez-Piñeiro, J., Sáez García, J., Barruso, P. (eds.), Geografia e Historia de DonostiaSan Sebastián: Donostia-San Sebastián, Instituto Geográfico Vasco, 16-28.
Edeso-Fito, J.M., Mujika-Alustiza, J.A., 2005, El entorno de Zarautz durante el Cuaternario. Evolución paisajística, ambiental y humana: Zarautz (España), Museo de Arte e Historia de Zarautz, 119 p.

Edeso-Fito, J.M., Lopetegi-Galarraga, A., MujikaAlustiza, J.A., 2014, Niveles marinos en Jaizkibel: interpretación sedimentaria y dinámica geomorfológica cuaternaria: Munibe Monographs Nature Series, 2, 57-78.

Feuillée, P., Rat, P., 1971, Structures et paléogéographies pyrénéo-cantabriques, en Debyser, J., Le Pichon, X., Montardet, L. (eds.), Histoire structural du Golfe de Gascogne: Paris, l'Inst. Français Pétrole, $1-48$.

Fleming, K., Johnston, P., Zwartz, D., Yokoyama, Y., Lambeck, K., Chappell, J., 1998, Refining the eustatic sea-level curve since the Last Glacial Maximum using far- and intermediate-field sites: Earth and Planetary Science Letters, 163, 327-342.

Flor, G., 1983, Las rasas asturianas: ensayos de correlación y emplazamiento: Trabajos de Geología, 13, 65-81.

Flor, G., Lharti, S., 2008, Estratigrafia y sedimentología del recubrimiento costero de la ciudad de Gijón (Asturias): Trabajos de Geología, 28, 135-157.

Folk, R.L., 1974, The petrology of sedimentary rocks: Austin, Texas Hemphill Publishing Co., $182 \mathrm{p}$.

Folk, R.L., Ward, W., 1957, Brazos River Bar: a study on the significance of grain size parameters: Journal of Sedimentary Research, 27, 3-26.

Galván, C., 2014, Clasificación de estuarios a diferentes escalas espaciales mediante la integración de modelos físicos y biológicos: Santander, España, Universidad de Cantabria, tesis doctoral, $504 \mathrm{p}$.

Garrote, A., García-Portero, J., Muñoz-Jiménez, L., 1990, Mapa Geológico de San Sebastián 64-II: Madrid, España, 1 mapa. 
Geoportal-geoEuskadi, 2015, Geoportal de la Infraestructura de Datos Espaciales (IDE) de Euskadi, disponible en <http://www.geo. euskadi.eus>, consultado 26 de julio de 2016.

Gómez-Piñeiro, J., Orella, J.L., Saez García, J.A., 1994, Documentos Cartográficos Históricos de Gipuzkoa: San Sebastián, Diputación Foral de Gipuzkoa, 311 p.

González, M., Uriarte, A., Fontán, A., Mader, J., Gyssels, P., 2004, Marine dynamics, en Borja, A., Collins, M. (eds.), Oceanography and Marine Environment of the Basque Country: Amsterdam, Elsevier Oceanography Series, 133-157.

González-Amuchástegui, M.J., Serrano-Cañadas, E., Edeso-Fito, J.M., Meaza-Rodríguez, G., 2005, Cambios en el nivel del mar durante el Cuaternario y morfología litoral en la costa oriental de Cantabria (País Vasco y Cantabria) (resumen), en Geomorfologia litoral i Quaternari: Valencia, España, PUV, $167-180$

Gornitz, V., 2013, Rising Seas: Past, Present, and Future: New York, Columbia University Press, $360 \mathrm{p}$.

Hather, J.G., 2000, The identification of the Northern European woods. A guide for archaeologists and conservators: Londres, Archetype Publications, 197 p.

Hayes, M.O., 1975, Morphology of sand accumulation in estuaries; an introduction to the symposium, en Cronin, L.E. (ed.), Estuarine Research: New York, Academic Press, 3-22.

Hume, T.H., Snelder, T., Watherhead, M., Liefting, R., 2007, A controlling factor approach to estuary classification: Ocean \& Coastal Management, 50, 905-929.

Ibáñez, C., Caiola, N., Nebra, A., Wessels, M., 2009, Estuarios, en VVAA (eds.), Bases ecológicas preliminares para la conservación de los tipos de hábitat de interés comunitario en España: Madrid, Ministerio de Medio Ambiente, y Medio Rural y Marino, 73 p.
Ketchum, B.H., 1983, Ecosystems of the World, 26: Estuaries and enclosed seas: Amsterdam, Elsevier Scientific, 500 p.

Leorri, E., Cearreta, A., 2009, Antropocene versus Holocene relative sea-level rise rates in the southern Bay of Biscay: Geogaceta, 46, 127-130.

Leorri, E., Cearreta, A., Milne, G., 2012, Field observations and modelling of Holocene sealevel changes in the southern Bay of Biscay: implication for understanding current rates of relative sea-level change and vertical land motion along the Atlantic coast of SW Europe: Quaternary Science Reviews, 42, 59-73.

Liu, J.P., Milliman, J.D., 2004, Reconsidering Melt-water Pulses 1A and 1B: Global Impacts of Rapid Sea-level Rise: Journal of Ocean University of China, 3, 183-190.

Lopetegi-Galarraga, A., 2011, Caracterización granulométrica de depósitos litorales actuales en Gipuzkoa: Hondarribia-Getaria: CKQ, 1, 89-114.

Lopetegi-Galarraga, A., Edeso-Fito,J. M., MujikaAlustiza, J.A., 2014, Niveles transgresivos recientes entre las desembocaduras del Bidasoa y del Oiartzun-Bahía de Pasajes (Gipuzkoa): Munibe Monographs. Nature Series, 2, 25-46.

Mary, G., 1979, Evolution de la bordure côtière asturienne (España) du Néogène a l'actuel: Caen, Francia, Universidad de Caen, tesis doctoral, $284 \mathrm{p}$.

Meriaux, S., 1953, Contribution à l'étude de l'Analyse granulométrique: París, Francia, Universidad de París, 118 p.

Milliman, J.D., Emery, K.O., 1968, Sea levels during the past 35000 years: Science, 162, $1121-1123$

Milne, G.A., Long, A. J., Bassett, S.E., 2005, Modelling Holocene relative sea-level observations from the Caribbean and South America: Quaternary Science Reviews, 24, 1183-1202. 
Mujika-Alustiza, J.A., Edeso-Fito, J.M., 2011, Los primeros agricultores y ganaderos en Gipuzkoa del Neolítico a la Edad del Hierro: Donostia-San Sebastián, España, Diputación Foral de Gipuzkoa, 385p.

Powers, M.C., 1953, A new roundness scale for sedimentary particles: Journal of Sedimentary Petrology: 23, 117-119.

Reineck, H.E., Singh, I.B., 1980, Depositional Sedimentary Environments: New York, Spinger-Verlag, 549 p.

Rey, J.M., Vilaseco, X.I., 2012, Guidiuri areoso. Megalithic cemetery and prehistoric settlement in the ria de Arousa (Galicia, NW Spain), en Campar Almeida, A., Bettencourt, A. M. S., Moura, D., Monteiro-Rodrigues, S., Caetano Alves, M. I. (eds.), Environmental changes and human interaction along the western Atlantic edge. Mudanças ambientais e interação humana nafachada atlântica occidental: Coimbra, Associação Portuguesa para o Estudo do Quaternário, 243-258.

Rivas, V., Cendrero, A., 1992, Análisis histórico de la evolución superficial de los estuarios del País Vasco: Lurralde 15, 195-224.

Salas, L., Remondo,J., Martínez, P., 1996, Cambios del nivel del mar durante el Holoceno en el Cantábrico a partir del estudio de la Turbera de Trengandín (resumen), en IV Reunión de Geomorfología: A Coruña, España, 237-247.

Sanjaume, E., 1985, Las costas valencianas: sedimentología y morfología: Valencia, Universidad de Valencia, 505 p.

Schweingruber, F.H., 1990, Anatomie europäischer Hölzer: ein Atlas zur Bestimmung europäischer Baum-, Strauchund Zwergstrauchhölzer (Anatomy of European woods an atlas for the identification of European trees shrubs and dwarf shrubs): Berna, Verlag P. Haupt, 800 p.
Shepard, F.P., 1963, Submarine Geology: New York, Harper and Row, 557 p.

Tenore, K.R., Zajac, R.N., Terwin, J., Andrade, F., Blanton, J., Boynton, W., Carey, D., Diaz, R., Holland, A.F., Lopez-Jamar, E., Montagna, P., Nichols, F., Rosenberg, R., Queiroga, H., Sprung, M., Whitlatch, R.B., 2006, Characterizing the role benthos palys in large coastal seas and estuaries: A modular approach: Journal of Experimental Marine Biology and Ecology, 330, 392-402.

Vatan, A., 1967, Manuel de sédimentologie: París, Éditions Technip, 397 p.

Vera, J.A., 2004, Geología de España: Madrid, SGE-IGME, $890 \mathrm{p}$.

Vernet, J.L., Ogereau, P., Figueiral, I., Machado, C., Uzquiano, P., 2001, Guide d'identification des charbons de bois préhistoriques et récents. Sud-Ouest de 1'Europe: France, Péninsule Ibérique et Îles Canaries: París, CNRS Éditions, 395 p.

Vilas, F., 1989. Estuarios y llanuras intermareales, en Arche, A. (ed.), Sedimentología: Madrid, CSIC, 451-491.

Vilas, F., Sopeña, A., Rey, L., Ramos, A. Nombela, M.A., Arche, A., 1991, The Corrubedo beach-lagoon complex, Galicia, Spain: Dynamics, sediments and recent evolution of a mesotidal coastal embayment: Marine Geology, 97, 391-404.

Visher, G.S., 1969, Grain-size distributions and depositional processes: Journal of Sedimentary Petrology, 39, 1074-1106. 